Article

\title{
Empagliflozin Attenuates Myocardial Sodium and Calcium Dysregulation and Reverses Cardiac Remodeling in Streptozotocin-Induced Diabetic Rats
}

\author{
Ting-I Lee ${ }^{1,2,3}$, Yao-Chang Chen ${ }^{4}$, Yung-Kuo Lin ${ }^{2,5}$, Cheng-Chih Chung ${ }^{2,5}$, Yen-Yu Lu ${ }^{6,7}$, \\ Yu-Hsun Kao ${ }^{8,9}$ and Yi-Jen Chen ${ }^{5,8, *}$ \\ 1 Department of General Medicine, School of Medicine, College of Medicine, Taipei Medical University, \\ Taipei 11031, Taiwan; agleems29@gmail.com \\ 2 Department of Internal Medicine, School of Medicine, College of Medicine, Taipei Medical University, \\ Taipei 11031, Taiwan; yklin213@yahoo.com.tw (Y.-K.L.); michaelchung110@gmail.com (C.-C.C.) \\ 3 Division of Endocrinology and Metabolism, Department of Internal Medicine, Wan Fang Hospital, \\ Taipei Medical University, Taipei 11696, Taiwan \\ 4 Department of Biomedical Engineering, National Defense Medical Center, Taipei 11490, Taiwan; \\ bme02@ndmctsgh.edu.tw \\ 5 Cardiovascular Research Center, Wan Fang Hospital, Taipei Medical University, Taipei 11696, Taiwan \\ 6 Division of Cardiology, Department of Internal Medicine, Sijhih Cathay General Hospital, \\ New Taipei City 22174, Taiwan; yolu59@yahoo.com.tw \\ 7 School of Medicine, Fu-Jen Catholic University, New Taipei City 22174, Taiwan \\ 8 Graduate Institute of Clinical Medicine, College of Medicine, Taipei Medical University, \\ Taipei 11031, Taiwan; yuhsunkao@gmail.com \\ 9 Department of Medical Education and Research, Wan Fang Hospital, Taipei Medical University, \\ Taipei 11696, Taiwan \\ * Correspondence: yjchen@tmu.edu.tw or a9900112@ms15.hinet.net
}

Received: 18 February 2019; Accepted: 2 April 2019; Published: 4 April 2019

\begin{abstract}
Diabetes mellitus (DM) has significant effects on cardiac calcium $\left(\mathrm{Ca}^{2+}\right)$ and sodium $\left(\mathrm{Na}^{+}\right)$regulation. Clinical studies have shown that empagliflozin (Jardiance ${ }^{\mathrm{TM}}$ ) has cardiovascular benefits, however the mechanisms have not been fully elucidated. This study aimed to investigate whether empagliflozin modulates cardiac electrical activity as well as $\mathrm{Ca}^{2+} / \mathrm{Na}^{+}$homeostasis in DM cardiomyopathy. Electrocardiography, echocardiography, whole-cell patch-clamp, confocal microscopic examinations, and Western blot, were performed in the ventricular myocytes of control and streptozotocin-induced DM rats, with or without empagliflozin (10 mg/kg for 4 weeks). The results showed that the control and empagliflozin-treated DM rats had smaller left ventricular end-diastolic diameters and shorter QT intervals than the DM rats. In addition, the prolonged action potential duration in the DM rats was attenuated in the empagliflozin-treated DM rats. Moreover, the DM rats had smaller sarcoplasmic reticular $\mathrm{Ca}^{2+}$ contents, intracellular $\mathrm{Ca}^{2+}$ transients, L-type $\mathrm{Ca}^{2+}$, reverse mode $\mathrm{Na}^{+}-\mathrm{Ca}^{2+}$ exchanger currents, lower protein expressions of sarcoplasmic reticulum ATPase, ryanodine receptor 2 (RyR2), but higher protein expressions of phosphorylated RyR2 at serine 2808 than the control and empagliflozin-treated DM rats. The incidence and frequency of $\mathrm{Ca}^{2+}$ sparks, cytosolic and mitochondrial reactive oxygen species, and late $\mathrm{Na}^{+}$ current and $\mathrm{Na}^{+}$/hydrogen-exchanger currents were greater in the DM rats than in the control and empagliflozin-treated DM rats. Empagliflozin significantly changed $\mathrm{Ca}^{2+}$ regulation, late $\mathrm{Na}^{+}$and $\mathrm{Na}^{+} /$hydrogen-exchanger currents and electrophysiological characteristics in DM cardiomyopathy, which may contribute to its cardioprotective benefits in DM patients.
\end{abstract}

Keywords: Sodium glucose co-transporter 2 inhibitor; diabetes mellitus; calcium handling; sodium regulation; cardiomyocytes 


\section{Introduction}

Cardiovascular (CV) complications are major causes of mortality in patients with both type 1 and type 2 diabetes mellitus (DM) [1,2]. DM cardiomyopathy is common in DM patients, and involves complex interactions of impaired mechanical functions and electrical abnormalities, leading to arrhythmogenesis [3,4]. Sodium glucose co-transporter (SGLT) 2 inhibitors are novel anti-DM agents that lower blood glucose levels by promoting urinary glucose excretion in patients with type 2 DM [5]. In addition, studies have also shown that SGLT2 inhibitors are effective adjunct therapy for glycemic control in patients with type 1 DM [6,7]. Empagliflozin, a highly selective SGLT2 inhibitor [8], has demonstrated CV benefits with a $38 \%$ reduction in the relative risk of $\mathrm{CV}$ death, and a $35 \%$ risk reduction in hospitalization for heart failure in DM patients [9]. However, the mechanisms behind the improved $\mathrm{CV}$ outcomes in patients receiving empagliflozin are unclear.

Homeostasis of calcium $\left(\mathrm{Ca}^{2+}\right)$ and sodium $\left(\mathrm{Na}^{+}\right)$in the heart is important to appropriately regulate heart rhythm, myocardial signal transduction, energy production and respiration of the myocardium [10]. DM is associated with cardiac electrical disturbances and $\mathrm{Ca}^{2+}$ dysregulation [11]. In addition, both $\mathrm{Ca}^{2+}$ and $\mathrm{Na}^{+}$transport have been shown to be altered in the hearts of patients with DM $[12,13]$. Previous studies have shown that different anti-DM agents may have various effects on cardiac electrical properties in animal models and in vitro [14-16]. The anti-DM agent, sitagliptin, a dipeptidyl peptidase-4 inhibitor, has been shown to have anti-inflammatory and antihypertensive potential which can attenuate hypertensive-induced electrical disturbances [15]. However, the peroxisome proliferator-activated receptor- $\gamma$ agonist, rosiglitazone, has been shown to increase cardiac arrhythmogenesis through dysregulated $\mathrm{Ca}^{2+}$ homeostasis and prolonged action in DM hypertensive rats [14]. Accordingly, we hypothesized that empagliflozin may modulate $\mathrm{Ca}^{2+}$ and $\mathrm{Na}^{+}$homeostasis in DM cardiomyopathy, contributing to its effects on CV outcomes. Therefore, the purpose of this study was to investigate whether empagliflozin modulates cardiac electrical and structural remodeling in DM.

\section{Results}

\subsection{Cardiac Structure and Electrocardiography of Control, DM, and Empagliflozin-Treated DM Rats}

Table 1 summarizes the blood glucose, systolic and diastolic blood pressures (BPs), body weight, and heart size of the studied animals. Compared to the control rats $(5.1 \pm 0.1 \mathrm{mM}, \mathrm{N}=7)$, both the DM rats $(20.7 \pm 2.0 \mathrm{mM}, \mathrm{N}=7)$ and empagliflozin-treated $\mathrm{DM}$ rats $(10.0 \pm 1.3 \mathrm{mM}, \mathrm{N}=7)$ had higher blood glucose levels $(p<0.005)$. However, the empagliflozin-treated DM rats had lower levels of blood glucose than the DM rats $(p<0.005)$. Systolic and diastolic BPs were similar in the control, DM, and empagliflozin-treated DM rats. However, the DM rats $(345.5 \pm 16.0 \mathrm{bpm})$ had a lower heart rate compared to the control $(441.6 \pm 10.8, \mathrm{bpm} p<0.005)$ and empagliflozin-treated rats $(394.4 \pm 16.0 \mathrm{bpm}$, $p<0.05)$ after treatment. Body weights were similar among the three groups before treatment, however lower body weights after treatment were noted in the DM $(278.2 \pm 14.9 \mathrm{~g}, p<0.005)$ and empagliflozin-treated DM $(296.2 \pm 11.9 \mathrm{~g}, p<0.005)$ groups than in the control $(423.3 \pm 10.3 \mathrm{~g})$ group. Absolute heart weights were similar in the three groups, however the DM rats $(5.4 \pm 0.3 \mathrm{~g} / \mathrm{kg})$ had a greater heart-to-body weight ratio than the control, $(3.2 \pm 0.1 \mathrm{~g} / \mathrm{kg}, p<0.005)$ and than the empagliflozin-treated DM rats $(4.4 \pm 0.1 \mathrm{~g} / \mathrm{kg}, p<0.05)$.

As shown in Table 2, at 16 weeks the DM rats had higher left ventricle end-diastolic diameter (LVEDd), LV end-systolic diameter (LVESd), end-diastolic volume (EDV), end-systolic volume (ESV); and lower ejection fraction (EF) and fractional shortening (FS) values, compared to the control and empagliflozin-treated DM rats. In addition, the DM rats had longer QT intervals $(90 \pm 2 \mathrm{~ms}$ ) and corrected QT intervals (QTc) $(190 \pm 4 \mathrm{~ms})$ than either the control (QT $=70 \pm 2 \mathrm{~ms}$, $p<0.01 ; \mathrm{QTc}=170 \pm 10 \mathrm{~ms}, p<0.005)$ or empagliflozin-treated DM rats (QT = $70 \pm 1 \mathrm{~ms}, p<0.005$; $\mathrm{QTc}=160 \pm 3 \mathrm{~ms}, p<0.005$, Figure 1A). However, RR intervals were similar among the three groups rat. 
Moreover, measurements of the cross-sectional area in isolated single ventricular myocytes in confocal microscopic examinations showed a larger cell size in the DM group $\left(3004 \pm 81 \mu \mathrm{m}^{2}, n=88\right)$ than in the control $\left(2801 \pm 57 \mu \mathrm{m}^{2}, n=100, p<0.05\right)$ and empagliflozin-treated DM $\left(2635 \pm 77 \mu \mathrm{m}^{2}\right.$, $n=101, p<0.005)$ groups.

A

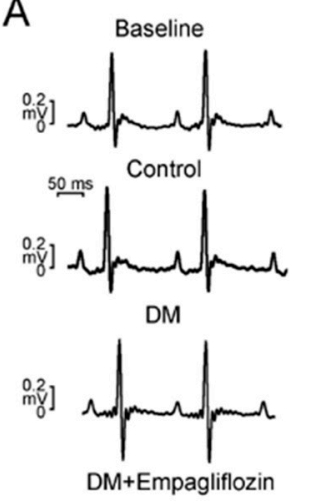

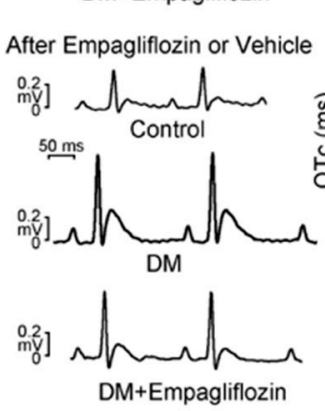
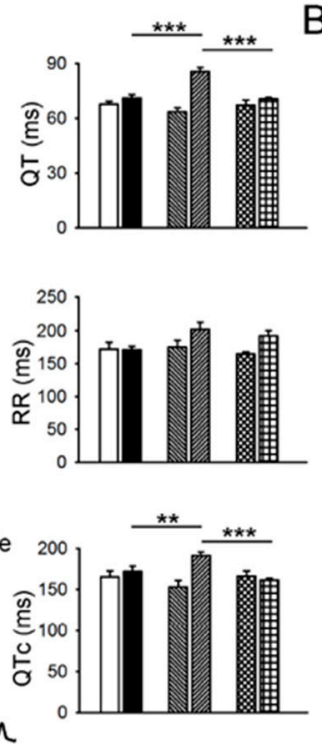

口 Control before vehicle Control after vehicle
an before vehicle $\mathrm{DM}$ before vehicle
$\mathrm{DM}$ after vehicle $\approx$ DM before Empagliflozin $\infty \mathrm{DM}$ after Empagliflozin
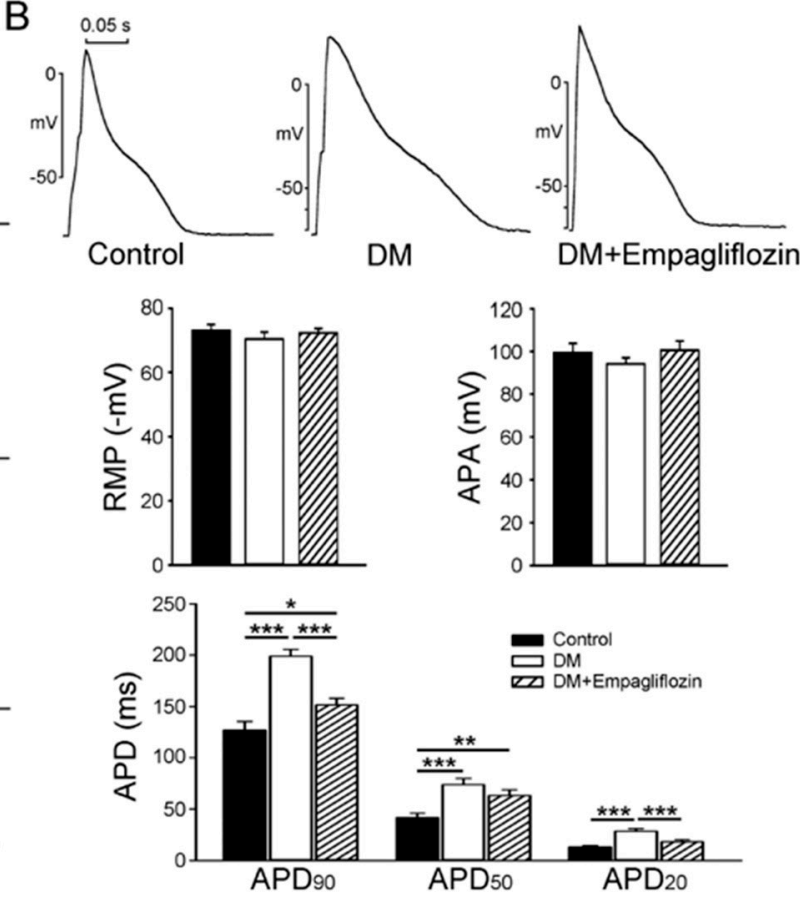

Figure 1. Electrocardiographic changes and action potentials (APs) of ventricular myocytes in control, diabetes mellitus (DM), and empagliflozin-treated DM (DM + empagliflozin) rats. (A) Representative electrocardiographic tracings and average data before and after treatment in control $(\mathrm{N}=7), \mathrm{DM}$ $(\mathrm{N}=7)$, and $\mathrm{DM}+$ empagliflozin $(\mathrm{N}=7)$ rats. (B) Representative tracings and average data of APs in control $(n=16), \mathrm{DM}(n=16)$, and DM + empagliflozin ventricular myocytes $(n=15)$. QT: QT interval; RR: RR interval; QTc: Corrected QT interval; $\mathrm{N}=$ number of rats; $n=$ number of cardiomyocytes isolated from those rats; RMP: Resting Membrane Potential; APA: Action Potential Amplitude; $\mathrm{APD}_{20}$, $\mathrm{APD}_{50}$, and $\mathrm{APD}_{90}$ : Action potential durations at $20 \%, 50 \%$, and $90 \%$ of repolarization, respectively; ${ }^{*} p<0.05 ;{ }^{* *} p<0.01 ;{ }^{* * *} p<0.005$.

Table 1. Physical characteristics of the control, diabetes mellitus (DM), and empagliflozin-treated DM rats at 10 (baseline) and 16 weeks of age (after treatment).

\begin{tabular}{lccc}
\hline \multicolumn{1}{c}{ Physical Characteristics } & Control & DM & Empagliflozin-Treated DM \\
\hline Baseline FBG (mM) & $4.7 \pm 0.2$ & $4.7 \pm 0.3$ & $4.7 \pm 0.1$ \\
FBG (mM) 2 weeks after streptozotocin & 4.7 & $20.1 \pm 0.7^{\mathrm{a}}$ & $20.1 \pm 0.9^{\mathrm{a}}$ \\
FBG (mM) after empagliflozin treatment & $5.1 \pm 0.1$ & $20.7 \pm 2.0^{\mathrm{a}}$ & $10.0 \pm 1.3^{\mathrm{a}, \mathrm{b}}$ \\
Baseline SBP (mmHg) & $110.1 \pm 1.6$ & $120.4 \pm 4.4$ & $114.6 \pm 3.9$ \\
SBP (mmHg) after treatment & $123.4 \pm 7.6$ & $122.7 \pm 8.4$ & $120.2 \pm 7.2$ \\
Baseline DBP (mmHg) & $64.2 \pm 3.2$ & $63.9 \pm 3.1$ & $62.2 \pm 3.6$ \\
DBP (mmHg) after treatment & $64.2 \pm 3.2$ & $64.6 \pm 3.2$ & $63.9 \pm 5.5$ \\
Baseline HR (bpm) & $414.4 \pm 15.9$ & $423.8 \pm 14.5$ & $421.8 \pm 14.1$ \\
HR (bpm) after treatment & $441.6 \pm 10.8$ & $345.5 \pm 16.0^{\mathrm{a}}$ & $394.4 \pm 16^{\mathrm{a}, \mathrm{b}}$ \\
Baseline BW (gm) & $332.4 \pm 4.8$ & $323.7 \pm 5$ & $326.1 \pm 7$ \\
BW (gm) after treatment & $423.3 \pm 10.3$ & $278.2 \pm 14.9^{\mathrm{a}}$ & $296.2 \pm 11.9^{\mathrm{a}, \mathrm{b}}$ \\
HW (gm) after treatment & $1.3 \pm 0.0$ & $1.5 \pm 0.1$ & $1.4 \pm 0.1$ \\
HW/BW ratio (gm/kg) after treatment & $3.2 \pm 0.1$ & $5.4 \pm 0.3^{\mathrm{a}}$ & $4.4 \pm 0.1^{\mathrm{a}, \mathrm{b}}$ \\
\hline
\end{tabular}

Abbreviations: FBG: Fasting Blood Glucose; SBP: Systolic Blood Pressure; DBP: Diastolic Blood Pressure; HR: Heart Rate; bpm: Beats Per Minute; BW: Body Weight; HW: Heart Weight. Values are expressed as the mean \pm SEM; Number of rats: 7 per group. ${ }^{\mathrm{a}} p<0.005$ compared to the controls; ${ }^{\mathrm{b}} p<0.05, p<0.005$ compared to the DM rats. 
Table 2. Echocardiograms of control, diabetes mellitus (DM), and empagliflozin-treated DM rats at 16 weeks.

\begin{tabular}{ccccccc}
\hline Group Studied & $\begin{array}{c}\text { LVEDd } \\
(\mathbf{m m})\end{array}$ & $\begin{array}{c}\text { LVESd } \\
\mathbf{( m m})\end{array}$ & EDV (mL) & ESV (mL) & EF (\%) & FS (\%) \\
\hline Control & $7.3 \pm 0.2^{\mathrm{a}}$ & $3.5 \pm 0.1$ & $0.9 \pm 0.1$ & $0.1 \pm 0.01$ & $87.7 \pm 0.7$ & $53.4 \pm 1.1$ \\
DM & $8.3 \pm 0.1^{\mathrm{a}}$ & $4.7 \pm 0.1^{\mathrm{a}}$ & $1.2 \pm 0.1^{\mathrm{a}}$ & $0.3 \pm 0.04^{\mathrm{a}}$ & $79.0 \pm 1.1^{\mathrm{a}}$ & $42.9 \pm 1.1^{\mathrm{a}}$ \\
$\begin{array}{c}\text { Empagliflozin-treated } \\
\text { DM }\end{array}$ & $7.3 \pm 0.1^{\mathrm{b}}$ & $3.7 \pm 0.1^{\mathrm{b}}$ & $0.9 \pm 0.0^{\mathrm{b}}$ & $0.1 \pm 0.04^{\mathrm{b}}$ & $85.4 \pm 1.5^{\mathrm{b}}$ & $49.8 \pm 1.7^{\mathrm{b}}$ \\
\hline
\end{tabular}

Abbreviations: LVEDd: Left Ventricular end-diastolic diameter; LVESd: Left Ventricular end-systolic diameter; EDV: End-diastolic Volume; ESV end-systolic volume; EF Ejection Fraction; FS: Fractional Shortening. Values are expressed as the mean \pm SEM. Number of rats: 7 per group; ${ }^{\mathrm{a}} p<0.005$ compared to the control rats; ${ }^{\mathrm{b}} p<0.005$ compared to the DM rats.

\subsection{Effects of Empagliflozin on Action Potentials (APs) in DM Rat}

$\mathrm{DM}$ rat ventricular myocytes had longer action potential duration $(\mathrm{APD})_{20}, \mathrm{APD}_{50}$, and $\mathrm{APD}_{90}$ $(28.4 \pm 2.5 \mathrm{~ms}, 73.9 \pm 6.0 \mathrm{~ms}, 198.8 \pm 6.8 \mathrm{~ms}, n=16)$ than thecontrol $(13.0 \pm 1.4 \mathrm{~ms}, 41.6 \pm 4.4 \mathrm{~ms}$, $126.8 \pm 8.6 \mathrm{~ms}, n=16, p<0.005)$ and empagliflozin-treated DM $(18.3 \pm 1.9 \mathrm{~ms}, p<0.005$; $63.4 \pm 5.4 \mathrm{~ms}, p<0.01 ; 151.4 \pm 6.5 \mathrm{~ms}, n=15, p<0.005$ ) ventricular myocytes (Figure 1B), however the control and empagliflozin-treated DM ventricular myocytes had similar APDs. Action potential amplitude (APA) and resting membrane potential (RMP) were similar in the control, DM, and empagliflozin-treated groups.

\subsection{Effects of Empagliflozin on $\mathrm{Ca}^{2+}$ Stores in DM Rats}

We evaluated $\mathrm{Ca}^{2+}$ homeostasis in the control, DM, and empagliflozin-treated DM ventricular myocytes. We found that the DM ventricular myocytes had reduced intracellular $\mathrm{Ca}^{2+}\left[\mathrm{Ca}^{2+}\right]_{\mathrm{i}}$ transients $\left(1.7 \pm 0.1 \mathrm{~F} / \mathrm{F}_{0}, n=45\right)$ than the control $\left(2.3 \pm 0.2 \mathrm{~F} / \mathrm{F}_{0}, n=46, p<0.05\right)$ and empagliflozin-treated DM $\left(2.4 \pm 0.3 \mathrm{~F} / \mathrm{F}_{0}, n=46, p<0.05\right)$ ventricular myocytes by $35 \%$ and $41.2 \%$, respectively. However, the control and empagliflozin-treated DM ventricular myocytes had similar $\left[\mathrm{Ca}^{2+}\right]_{\mathrm{i}}$ transients (Figure $2 \mathrm{~A}$ ). In addition, the decay time $(345 \pm 39 \mathrm{~ms})$ of $\left[\mathrm{Ca}^{2+}\right]_{\mathrm{i}}$ transients in the DM ventricular myocytes was significantly prolonged compared to the control $(168 \pm 28 \mathrm{~ms}, p<0.005)$ and empagliflozin-treated $\mathrm{DM}(228 \pm 32 \mathrm{~ms}, p<0.05)$ ventricular myocytes, whereas the control and empagliflozin-treated DM ventricular myocytes had similar decay times of $\left[\mathrm{Ca}^{2+}\right]_{i}$ transients. We measured the sarcoplasmic reticular (SR) $\mathrm{Ca}^{2+}$ content and found that the DM ventricular myocytes had significantly smaller $\mathrm{Ca}^{2+}$ stores $(30.8 \pm 4.3 \mu \mathrm{mol} / \mathrm{L}, n=13)$ as measured by integrating the $\mathrm{Na}^{+}-\mathrm{Ca}^{2+}$ exchanger (NCX) current after caffeine than the control $(48.2 \pm 8.0 \mu \mathrm{mol} / \mathrm{L}, n=16, p<0.05)$ and empagliflozin-treated DM $(49.7 \pm 8.0 \mu \mathrm{mol} / \mathrm{L}, n=15, p<0.05)$ ventricular myocytes (Figure $2 \mathrm{~B})$.

As shown in Figure $2 \mathrm{C}$, the incidence and frequency of $\mathrm{Ca}^{2+}$ sparks were evaluated in the different groups. The incidence and frequency of $\mathrm{Ca}^{2+}$ sparks were increased in the DM group $(9.2 \pm 1.7$ spark $/ \mathrm{mm} / \mathrm{s}, n=76)$ compared to the control $(1.0 \pm 0.2 \mathrm{spark} / \mathrm{mm} / \mathrm{s}, n=40, p<0.005)$ and empagliflozin-treated DM $(1.8 \pm 0.5 \mathrm{spark} / \mathrm{mm} / \mathrm{s}, n=36, p<0.005)$ ventricular myocytes. In addition, the DM ventricular myocytes had a longer duration and larger width of $\mathrm{Ca}^{2+}$ sparks $(48.0 \pm 1.9 \mathrm{~ms}, 4.8 \pm 0.2 \mu \mathrm{m})$ than the control $(35.8 \pm 2.7 \mathrm{~ms}, p<0.005 ; 2.8 \pm 0.2 \mu \mathrm{m}, p<0.005)$ and empagliflozin-treated DM $(40.0 \pm 2.1 \mathrm{~ms}, p<0.05 ; 3.7 \pm 0.2 \mu \mathrm{m}, p<0.005)$ ventricular myocytes. The peak amplitude of $\mathrm{Ca}^{2+}$ sparks was similar in the different groups. 
A
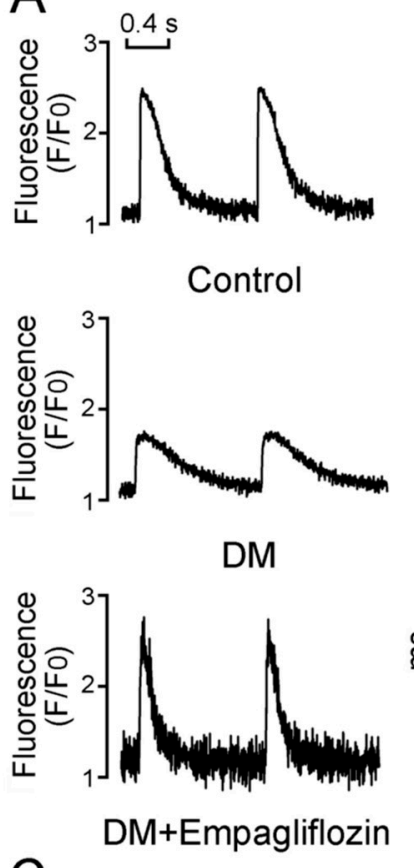

C

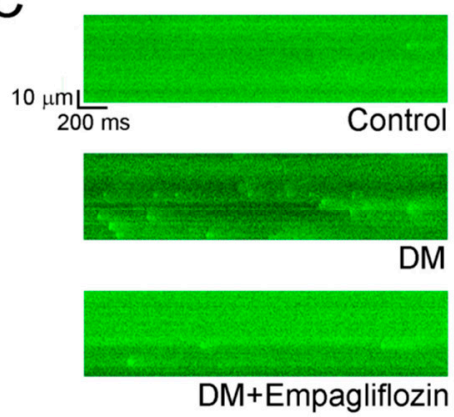

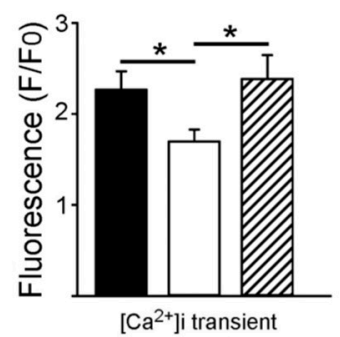

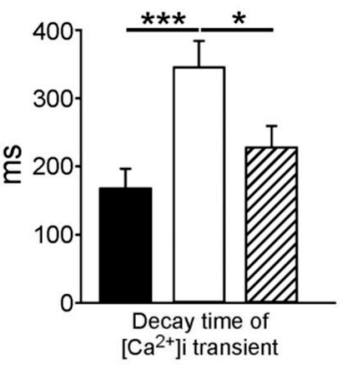

B
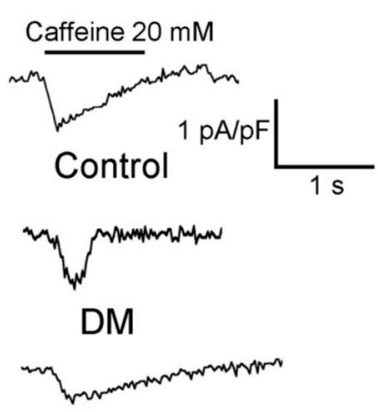

DM+Empagliflozin

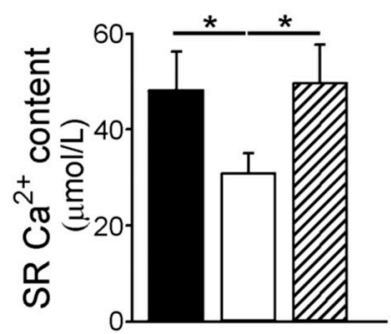

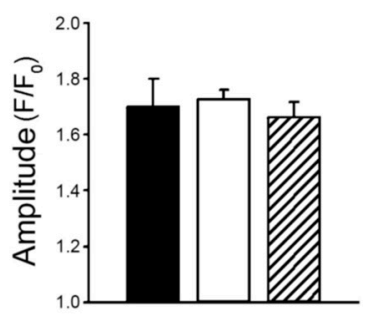
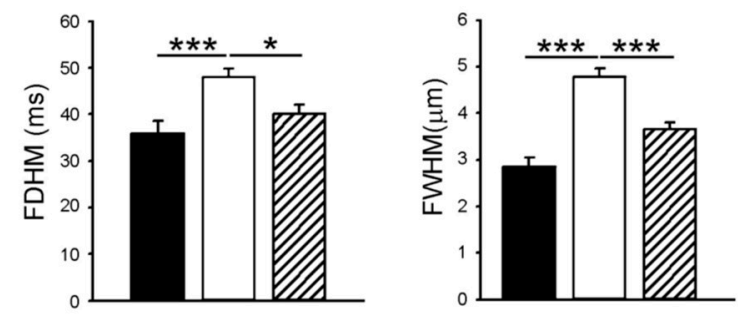

Figure 2. Intracellular $\mathrm{Ca}^{2+}\left(\left[\mathrm{Ca}^{2+}\right]_{\mathrm{i}}\right)$ transients, calcium $\left(\mathrm{Ca}^{2+}\right)$ stores measured from caffeine $(20 \mathrm{mM})$-induced $\mathrm{Ca}^{2+}$ transients and $\mathrm{Ca}^{2+}$ sparks in ventricular myocytes from control, diabetes mellitus (DM), and empagliflozin-treated DM (DM + empagliflozin) rats. (A) Representative tracings and average data of $\left[\mathrm{Ca}^{2+}\right]_{i}$ transients and decay of time of $\left[\mathrm{Ca}^{2+}\right]_{i}$ transients in the ventricular myocytes recorded from control $(n=46)$, DM $(n=45)$, and DM + empagliflozin $(n=46)$ rats. (B) Representative tracings and average data of $\mathrm{Ca}^{2+}$ stores of ventricular myocytes recorded from the control $(n=16)$, $\mathrm{DM}(n=13)$, and DM + empagliflozin $(n=15)$ rats. (C) Representative tracings and average data of the incidence, frequency, amplitude, duration (full duration at half-maximal amplitude, FDHM), and width (full-width at half-maximal amplitude, FWHM) of $\mathrm{Ca}^{2+}$ sparks in control $(n=40), \mathrm{DM}(n=76)$, and DM + empagliflozin $(n=36)$ ventricular myocytes. $n=$ number of cardiomyocytes isolated from those rats; ${ }^{*} p<0.05 ;{ }^{* * *} p<0.005$.

\subsection{Effects of Empagliflozin on L-type $\mathrm{Ca}^{2+}$ Channel $\left(I_{C a-L}\right)$ Current and NCX Current in DM Rats}

The current density of $\mathrm{I}_{\mathrm{Ca}-\mathrm{L}}$ in the $\mathrm{DM}$ ventricular myocytes was smaller than those in the control and empagliflozin-treated DM ventricular myocytes (Figure 3A). Figure 3B shows tracings 
and I-V relationships of nickel-sensitive NCX currents of ventricular myocytes from the control, DM, and empagliflozin-treated DM rats. The DM ventricular myocytes had a smaller reverse mode of nickel-sensitive NCX currents than the control and empagliflozin-treated DM ventricular myocytes.
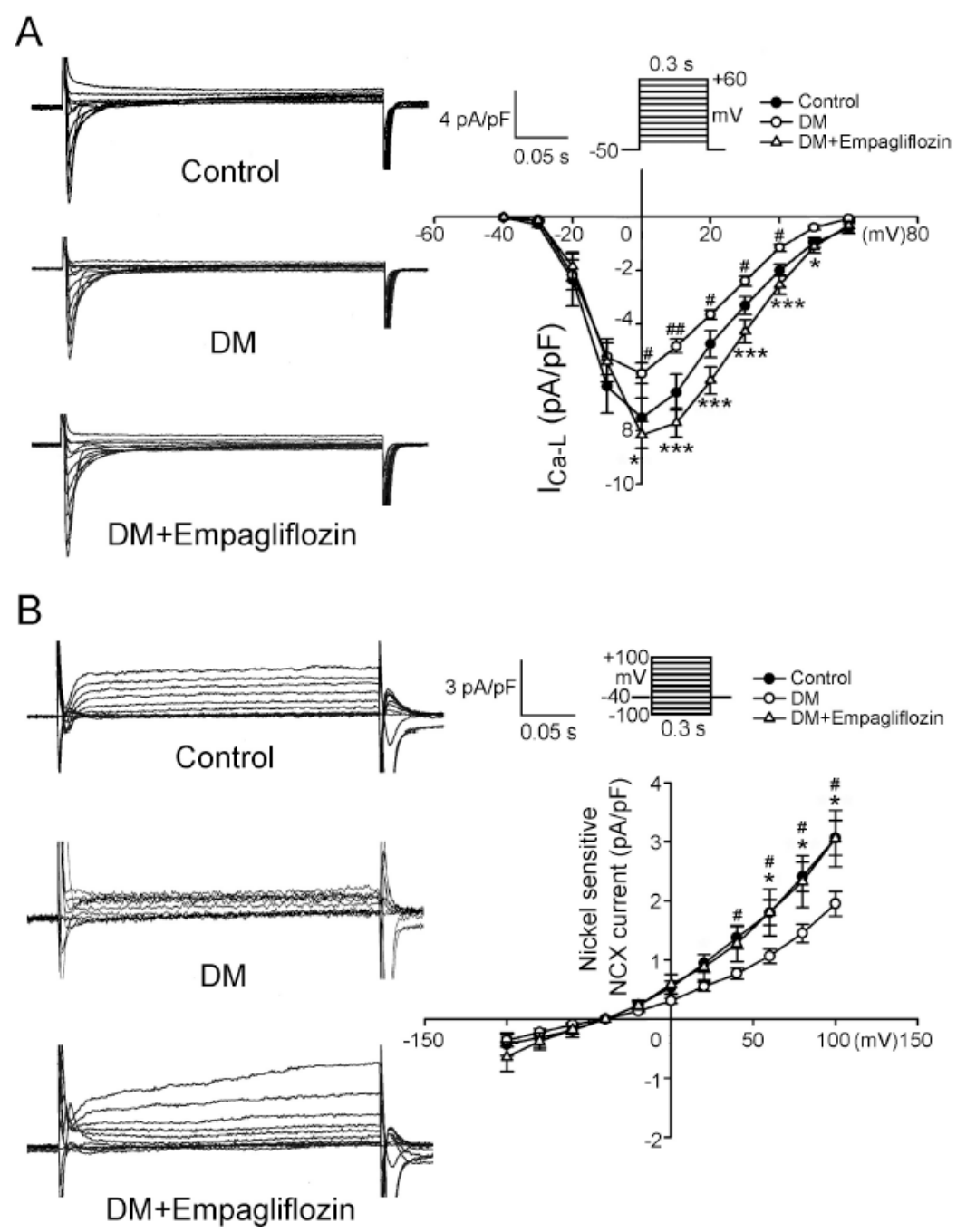

Figure 3. L-type calcium channel $\left(\mathrm{I}_{\mathrm{Ca}-\mathrm{L}}\right)$ and $\mathrm{Na}^{+}-\mathrm{Ca}^{2+}$ exchanger (NCX) current of ventricular myocytes from control, diabetes mellitus (DM), and empagliflozin-treated DM (DM + empagliflozin) rats. (A) Representative tracings of current and I-V relationship of the $\mathrm{I}_{\mathrm{Ca}-\mathrm{L}}$ of ventricular myocytes from control $(n=11)$, DM $(n=14)$, and DM + empagliflozin $(n=21)$ rats. (B) Representative tracings of current and I-V relationship of the NCX current of ventricular myocytes from control $(n=11)$, DM $(n=13)$, and DM + empagliflozin $(n=8)$ rats. $n=$ number of cardiomyocytes isolated from those rats; ${ }^{\#} p<0.05$ vs. the controls; ${ }^{\# \#} p<0.01$ vs. the controls; ${ }^{*} p<0.05$ vs. DM + empagliflozin rats; ${ }^{* * *} p<0.005$ vs. DM + empagliflozin rats.

2.5. Effects of Empagliflozin on Late $\mathrm{Na}^{+}$Channel $\left(\mathrm{I}_{\mathrm{Na}-\text { late }}\right)$ Current and $\mathrm{Na} / \mathrm{Hydrogen}\left(\mathrm{Na}^{+} / \mathrm{H}^{+}\right)$Exchanger Current in DM Rats

The current density of $\mathrm{I}_{\mathrm{Na}-\text {-late }}$ in the $\mathrm{DM}$ ventricular myocytes $(0.67 \pm 0.07 \mathrm{pA} / \mathrm{pF}, n=15)$ was greater than those in the control $(0.49 \pm 0.04 \mathrm{pA} / \mathrm{pF}, n=18, p<0.05)$ and empagliflozin-treated DM $(0.51 \pm 0.03 \mathrm{pA} / \mathrm{pF}, n=16, p<0.05)$ ventricular myocytes (Figure $4 \mathrm{~A})$. Figure $4 \mathrm{~B}$ shows tracings and current densities of $\mathrm{Na}^{+} / \mathrm{H}^{+}$exchanger currents of ventricular myocytes from the control, $\mathrm{DM}$, and empagliflozin-treated DM rats. 
The DM ventricular myocytes $(17.1 \pm 1.6 \mathrm{pA} / \mathrm{pF}, n=18)$ had a larger $\mathrm{Na}^{+} / \mathrm{H}^{+}$exchanger current than the control $(11.6 \pm 1.3 \mathrm{pA} / \mathrm{pF}, n=17, p<0.05)$ and empagliflozin-treated $\mathrm{DM}(12.1 \pm 1.1 \mathrm{pA} / \mathrm{pF}$, $n=19, p<0.05)$ ventricular myocytes.

A

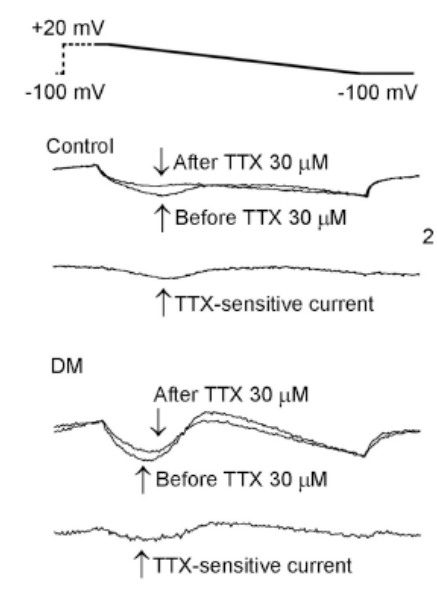

DM+Empagliflozin

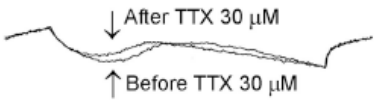
$2 \mathrm{pA} / \mathrm{pF} \frac{}{0.02 \mathrm{~s}}$

$\uparrow$ TTX-sensitive current

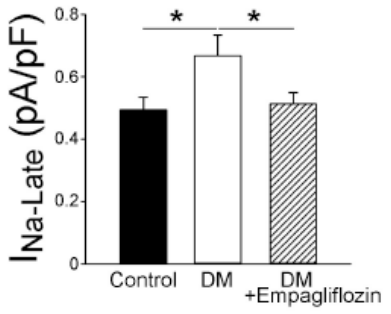

B
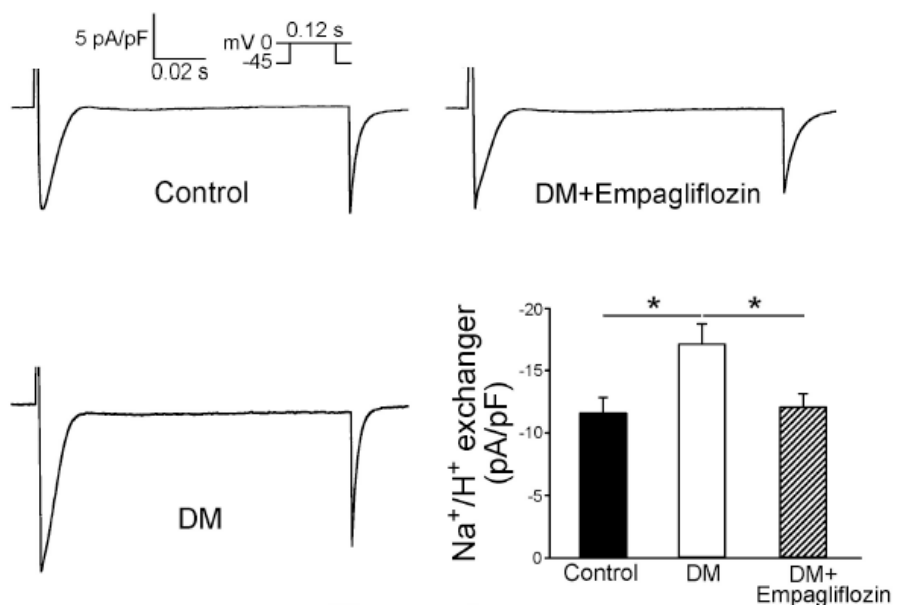

Figure 4. Late sodium current $\left(\mathrm{I}_{\mathrm{Na}-\text { Late }}\right)$ and sodium hydrogen $\left(\mathrm{Na}^{+} / \mathrm{H}^{+}\right)$exchanger current of ventricular myocytes from control, diabetes mellitus (DM), and empagliflozin-treated DM (DM + empagliflozin) rats. (A) Representative tracing of current and average data of the $\mathrm{I}_{\mathrm{Na} \text {-Late }}$ of ventricular myocytes from control $(n=18)$, DM $(n=15)$, and DM + empagliflozin $(n=16)$ rats. (B) Representative tracings of current and average data of the $\mathrm{Na}^{+} / \mathrm{H}^{+}$exchanger of ventricular myocytes from control $(n=17), \mathrm{DM}(n=18)$, and DM + empagliflozin $(n=19)$ rats. $n=$ number of cardiomyocytes isolated from those rats; ${ }^{*} p<0.05$.

\subsection{Effects of Empagliflozin on Oxidative Stress in DM Rats}

As shown in Figure 5A, the DM ventricular myocytes $\left(126 \pm 5 \mathrm{~F} / \mathrm{F}_{0}, n=28\right)$ had higher levels of cytosolic reactive oxygen species (ROS) than the control $\left(89 \pm 10 \mathrm{~F} / \mathrm{F}_{0}, n=21, p<0.005\right)$ and empagliflozin-treated DM $\left(88 \pm 5 \mathrm{~F} / \mathrm{F}_{0}, n=46, p<0.005\right)$ ventricular myocytes, by $28.8 \%$ and $29.8 \%$, respectively. The control and empagliflozin-treated DM ventricular myocytes had similar cytosolic ROS levels. In addition, the level of mitochondrial ROS in the DM ventricular myocytes $\left(41 \pm 1 \mathrm{~F} / \mathrm{F}_{0}\right.$, $n=38)$ was greater than those in the control $\left(23 \pm 1 \mathrm{~F} / \mathrm{F}_{0}, n=50, p<0.005\right)$ and empagliflozin-treated $\mathrm{DM}\left(37 \pm 2 \mathrm{~F} / \mathrm{F}_{0}, n=28, p<0.05\right)$ ventricular myocytes by $44.3 \%$ and $10.5 \%$, respectively (Figure $\left.5 \mathrm{~B}\right)$. Similarly, the intracellular $\mathrm{Na}^{+}\left(\left[\mathrm{Na}^{+}\right]_{\mathrm{i}}\right)$ level in the DM ventricular myocytes $\left(133 \pm 18 \mathrm{~F} / \mathrm{F}_{0}, n=22\right)$ was greater than those in the control $\left(115 \pm 22 \mathrm{~F} / \mathrm{F}_{0}, n=29, p<0.005\right)$ and empagliflozin-treated DM $\left(122 \pm 17 \mathrm{~F} / \mathrm{F}_{0}, n=27, p<0.05\right)$ ventricular myocytes by $13.2 \%$ and $7.8 \%$, respectively (Figure $5 \mathrm{C}$ ). 
A

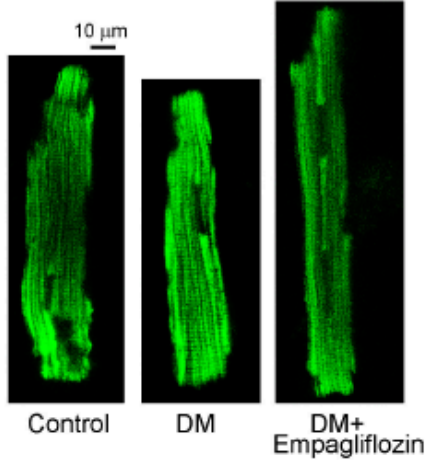

B

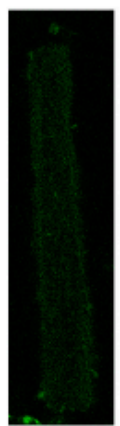

Control

C

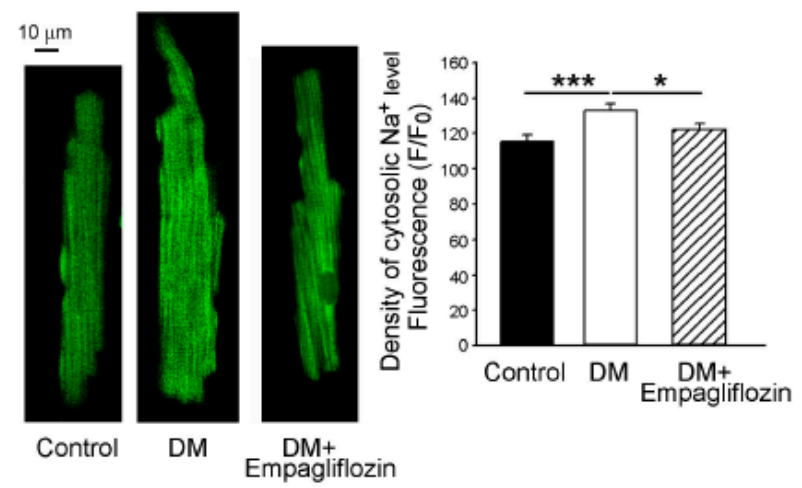

Figure 5. Oxidative stress and cytosolic sodium $\left(\mathrm{Na}^{+}\right)$levels in control, diabetes mellitus (DM), and empagliflozin-treated DM (DM + empagliflozin) ventricular myocytes. (A) An example and average data of cytosolic levels of reactive oxygen species (ROS) in control $(n=21)$, DM $(n=28)$, and DM + empagliflozin $(n=46)$ ventricular myocytes. (B) An example and average data of mitochondrial levels of ROS in control $(n=50)$, DM $(n=38)$, and DM + empagliflozin $(n=28)$ ventricular myocytes. (C) An example and average data of cytosolic $\mathrm{Na}^{+}$levels in control $(n=29)$, DM $(n=22)$, and $\mathrm{DM}+$ empagliflozin $(n=27)$ ventricular myocytes. $n=$ number of cardiomyocytes isolated from those rats; ${ }^{*} p<0.05 ;{ }^{* * *} p<0.005$.

\subsection{Acute Effects of Empagliflozin on DM Rat Ventricular Myocytes}

In order to study whether empagliflozin may directly affect cardiac disorder in DM rats, we investigated the acute effects of empagliflozin $(1 \mu \mathrm{M})$ on isolated DM rat cardiomyocytes. As shown in Figure 6, acute administration of empagliflozin $\left(1 \mu \mathrm{M}\right.$ ) reduced the $\mathrm{APD}_{90}$ (from $170 \pm 4 \mathrm{~ms}$ to $129 \pm 11 \mathrm{~ms}, n=10, p<0.01$ ), and $\mathrm{APD}_{50}$ (from $77 \pm 6 \mathrm{~ms}$ to $60 \pm 6 \mathrm{~ms}, n=10, p<0.05$ ) in DM ventricular myocytes. In addition, empagliflozin $(1 \mu \mathrm{M})$ reduced $\mathrm{I}_{\mathrm{Na} \text {-Late }}$ from $0.66 \pm 0.07 \mathrm{pA} / \mathrm{pF}$ to $0.28 \pm 0.04 \mathrm{pA} / \mathrm{pF}(n=11, p<0.005)$ and cytosolic ROS levels from $108 \pm 4 \mathrm{~F} / \mathrm{F}_{0}$ to $81 \pm 4 \mathrm{~F} / \mathrm{F}_{0}(n=11$, $p<0.005)$ in DM ventricular myocytes. 
A

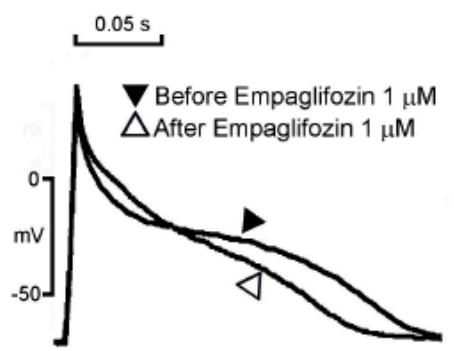

B

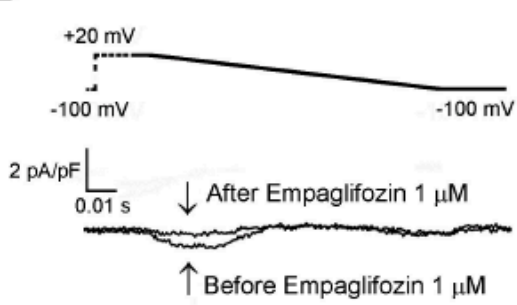
Before Empaglifozin $1 \mu \mathrm{M}$
After Empaglifozin $1 \mu \mathrm{M}$

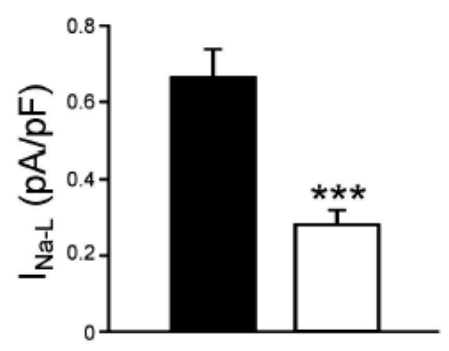

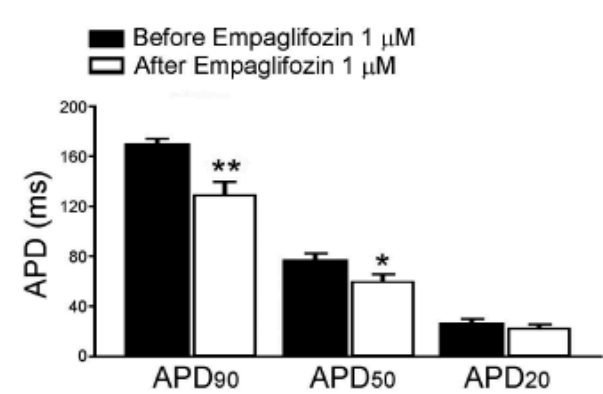

C
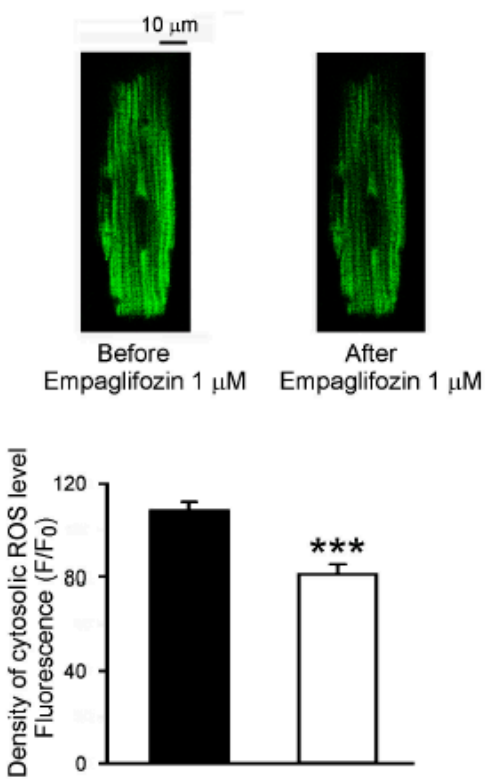

Figure 6. Acute effects of empagliflozin on DM ventricular myocytes. (A) The superimposed tracings and average data $(n=10)$ of AP morphology before and after acute administration of empagliflozin $(1 \mu \mathrm{M})$ in DM rat ventricular myocytes. (B) Representative superimposed tracing of current and average data $(n=11)$ of the $\mathrm{I}_{\mathrm{Na} \text {-Late }}$ before and after acute administration of empagliflozin $(1 \mu \mathrm{M})$ in DM rat ventricular myocytes. (C) An example and average data $(n=11)$ of cytosolic levels of reactive oxygen species (ROS) before and after acute administration of empagliflozin $(1 \mu \mathrm{M})$ in DM rat ventricular myocytes. ${ }^{*} p<0.05 ;{ }^{* *} p<0.01$; ${ }^{* * *} p<0.005$ versus before empagliflozin.

\subsection{Effects of Empagliflozin on $\mathrm{Ca}^{2+}$ Regulatory Proteins in DM Rats}

We compared the expressions of $\mathrm{Ca}^{2+}$ regulatory proteins in control, DM and empagliflozin-treated DM rat ventricles using Western blotting (Figure 7). The protein expressions of SERCA2a $(0.57 \pm 0.06$, relative to control, $p<0.005)$ and RyR2 $(0.69 \pm 0.09$ relative to control, $p<0.05)$ in the DM group $(\mathrm{N}=7)$ were downregulated, compared with those in control $(\mathrm{N}=7)$ and empagliflozin-treated DM groups $(0.98 \pm 0.09 ; 1.09 \pm 0.12$, relative to control, $\mathrm{N}=7$, Figure 7). In contrast, the protein level of RyR2-pS2808 in the DM group $(1.51 \pm 0.17$, relative to control, $\mathrm{N}=7)$ was higher than those in the control $(\mathrm{N}=7, p<0.05$ and empagliflozin-treated DM groups $(0.53 \pm 0.04$, relative to control, $p<0.005 ; \mathrm{N}=7$ ). 

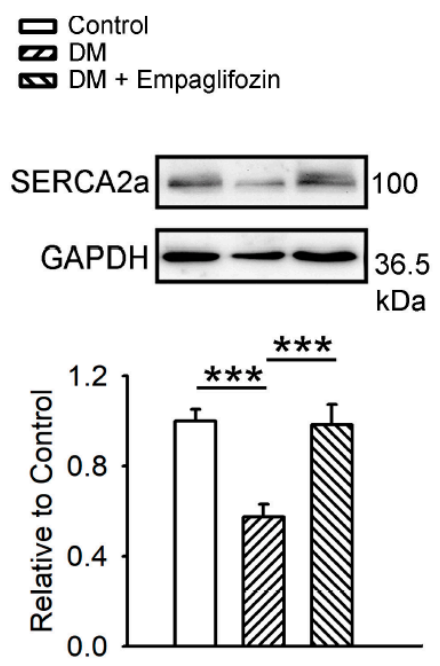
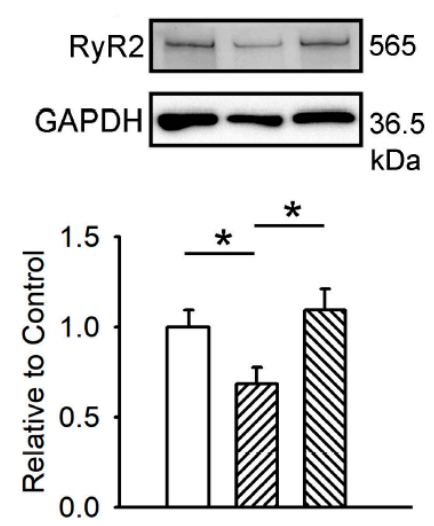
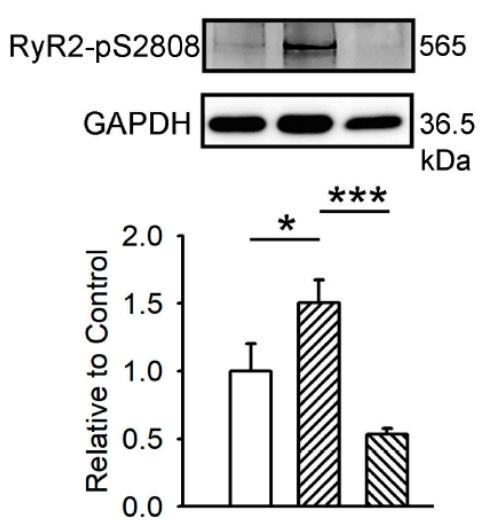

Figure 7. $\mathrm{Ca}^{2+}$ regulation proteins in control, diabetes mellitus (DM), and empagliflozin-treated $\mathrm{DM}(\mathrm{DM}+$ empagliflozin) ventricular myocytes. Representative immunoblot and average data of sarcoplasmic reticulum ATPase (SERCA2a), ryanodine receptor 2 (RyR2), and phosphorylated RyR2 at serine 2808 (RyR2-pS2808) from control $(\mathrm{N}=5), \mathrm{DM}(\mathrm{N}=5)$, and $\mathrm{DM}+$ empagliflozin $(\mathrm{N}=5)$ rat ventricular myocytes. Densitometry was normalized to glyceraldehyde 3-phosphate dehydrogenase $(\mathrm{GAPDH})$ as an internal control. $\mathrm{N}=$ number of rats; ${ }^{*} p<0.05 ;{ }^{* * *} p<0.005$.

\section{Discussion}

Altered expressions, activities and functions of transporters involved in excitation-contraction coupling, i.e., SERCA [17], NCX [18], and RyR [19], as well as dysfunction in [ $\left.\mathrm{Ca}^{2+}\right]_{\mathrm{i}}$ signaling [20] have been reported in DM rodent models. However, in the current investigation, we found that myocardial dysfunction, prolonged ventricular APs, decreased $\mathrm{Ca}^{2+}$ transients, increased $\mathrm{I}_{\mathrm{Na} \text {-late }}$ and $\mathrm{Na}^{+} / \mathrm{H}^{+}$-exchanger currents in the DM rats were attenuated after the administration of empagliflozin. Therefore, empagliflozin may affect the electromechanical mechanisms in DM cardiomyopathy.

DM patients have a high incidence of DM cardiomyopathy, characterized by complex changes in the mechanical and electrical properties of the heart [21]. DM patients usually present with prolongation of both QT and QTc intervals due to an increase in ventricular APD that makes them more susceptible to an increased incidence of arrhythmogenesis [22,23]. In this study, we found that the DM rats had a greater heart-to-body weight ratio and larger cross-sectional area of ventricular myocytes than the control and empagliflozin-treated groups. These findings are compatible with the results of a previous study [24]. The DM rats had prolonged QT and QTc intervals and ventricular APD, as we also demonstrated in our previous study [14]. Prolongation of the APD exacerbates the decrease in diastolic filling and stroke volume at high heart rates [25], and prolonged QT intervals may increase ventricular arrhythmia due to triggered activity of early afterdepolarization [14]. Moreover, we also found that empagliflozin changed the AP morphology and cardiac electrophysiology of the DM hearts. Reversed prolongation of the APD in the ventricular myocytes of DM rats after treatment suggests that empagliflozin may have a cardioprotective effect during electrophysiological alterations of DM hearts.

Lambert et al. found a higher $\left[\mathrm{Na}^{+}\right]_{\mathrm{i}}$ in late-onset type-2 DM rat myocytes which displayed a cardiac phenotype that closely resembled human DM cardiomyopathy [12]. The increase in $\mathrm{I}_{\mathrm{Na} \text {-late }}$ and $\mathrm{Na}^{+} / \mathrm{H}^{+}$-exchanger activity may contribute to the elevation of $\left[\mathrm{Na}^{+}\right]_{i}$ of DM myocytes, leading to $\mathrm{Ca}^{2+}$ overload, with an increased risk of arrhythmias and oxidative stress [26]. Similar to previous studies, our results showed that the ventricular myocytes of the DM rats had a reduced $\left[\mathrm{Ca}^{2+}\right]_{\mathrm{i}}$ transient amplitude, prolonged transient decay, and reduced $\mathrm{Ca}^{2+}$ store $[14,27,28] . \mathrm{Ca}^{2+}$ is one of the main ionic regulators of the heart, and it plays an important role in the process of excitation-contraction coupling. 
$\mathrm{Ca}^{2+}$ activates the release of further ionic $\mathrm{Ca}^{2+}$ from SR stores through RyR, which increases $\left[\mathrm{Ca}^{2+}\right]_{\mathrm{i}}$ and aids in the binding of $\mathrm{Ca}^{2+}$ to myofilaments and initiating cardiac contractions [29]. The decrease in $\left[\mathrm{Ca}^{2+}\right]_{i}$ transients in our DM hearts may have been caused by a decrease in $\mathrm{SR} \mathrm{Ca}^{2+}$ content, resulting in impaired excitation-contraction coupling efficiency and myocardial dysfunction. The reduction in SR $\mathrm{Ca}^{2+}$ stores might have been exacerbated in DM hearts due to a decrease in SERCA2a protein. We also found a prolonged $\left[\mathrm{Ca}^{2+}\right]_{\mathrm{i}}$ transient decay associated with the depletion of $\mathrm{SR} \mathrm{Ca}^{2+}$ contents in the DM hearts. The increase in the $\left[\mathrm{Ca}^{2+}\right]_{\mathrm{i}}$ transient decay may have been due to derangement in either the SERCA pump resulting in a decrease in the removal rate of cytoplasmic $\mathrm{Ca}^{2+}[18,27]$, and this may have caused impaired relaxation of the cardiomyocytes. The slower kinetics of the $\left[\mathrm{Ca}^{2+}\right]_{\mathrm{i}}$ transient of DM ventricular myocytes may also have been affected by the prolonged APD, altered $\left[\mathrm{Ca}^{2+}\right]_{\mathrm{i}}$ handling, or a combination of both. We also found that decreases in $\left[\mathrm{Ca}^{2+}\right]_{\mathrm{i}}$ transients and $\mathrm{Ca}^{2+}$ stores with prolonged $\left[\mathrm{Ca}^{2+}\right]_{i}$ decay in the DM hearts were attenuated in the DM rats treated with empagliflozin. These effects may have been caused by enhanced myocardial SERCA2a function as demonstrated in a previous study by Hammoudi et al. [30] resulting in increased reuptake of $\left[\mathrm{Ca}^{2+}\right]_{\mathrm{i}}$ after $\left[\mathrm{Ca}^{2+}\right]_{\mathrm{i}}$ release in the DM rats treated with empagliflozin. In addition, the $\mathrm{Ca}^{2+}$ regulatory effects of empagliflozin in DM hearts may have contributed to the improved cardiac function measured by echocardiography. The increase in SERCA2a protein in the DM rats treated with empagliflozin attenuated the negative impact of $\mathrm{DM}$ on $\mathrm{Ca}^{2+}$ dysregulation. These findings suggest that empagliflozin has potential to be a therapeutic strategy for cardiac electrical dysfunction in DM.

DM has been shown to modify $\mathrm{Ca}^{2+}$ entry through molecular mediators that permit the $\mathrm{Ca}^{2+}$ influx required for excitation-contraction coupling [31]. Several studies have shown that $\mathrm{Ca}^{2+}$ entry through voltage-dependent $\mathrm{I}_{\mathrm{Ca}-\mathrm{L}}$ is reduced in the cardiac myocytes of DM rodents [32-34]. $\mathrm{I}_{\mathrm{Ca}-\mathrm{L}}$ is a critical initiator of the contractile cycle in cardiac myocytes, and inhibition of $\mathrm{I}_{\mathrm{Ca}-\mathrm{L}}$ function has been reported to potentially reduce the entry of $\mathrm{Ca}^{2+}$ resulting in decreases in $\mathrm{Ca}^{2+}$ transients and contractile force [35]. This may also have caused the prolongation of QT and QTc intervals in electro-cardiography. Moreover, reversal of the $\mathrm{I}_{\mathrm{Ca}-\mathrm{L}}$ in the DM rats treated with empagliflozin may have contributed, at least in part, to the improved $\left[\mathrm{Ca}^{2+}\right]_{\mathrm{i}}$ transients and $\mathrm{SR} \mathrm{Ca}{ }^{2+}$ contents. In this study, the reverse mode $\left(\mathrm{Ca}^{2+}\right.$ influx) of NCX was depressed in the DM ventricular myocytes, indicating that a reduction in $\mathrm{Ca}^{2+}$ influx may have contributed to the decrease in $\left[\mathrm{Ca}^{2+}\right]_{\mathrm{i}}$. We also found that empagliflozin treatment restored the diminished NCX current.

$\mathrm{Ca}^{2+}$ sparks are brief releases of $\mathrm{Ca}^{2+}$ that are considered to be essential events in the excitation-contraction of cardiomyocyten addition, the frequency and incidence of $\mathrm{Ca}^{2+}$ sparks in the DM rats were also reversed after empagliflozin treatment. Thus, empagliflozin may have a beneficial effect in preventing increased $\mathrm{Ca}^{2+}$ leakage in the SR that may cause $\mathrm{Ca}^{2+}$ deficiency leading to myocardial dysfunction in DM cardiomyopathy. The decrease in RyR phosphorylation in DM hearts receiving empagliflozin may increase the amplitude of $\left[\mathrm{Ca}^{2+}\right]_{i}$ transients and improve myocardial contractility.

We evaluated the chronic in vivo effect of empagliflozin treatment on $\mathrm{I}_{\mathrm{Ca}-\mathrm{L}}$ and $\mathrm{Na}^{+}-\mathrm{H}^{+}$exchanger currents in DM ventricular myocytes. We demonstrated that chronic treatment with empagliflozin lowered intracellular $\mathrm{Na}^{+}$levels, and that $\mathrm{I}_{\mathrm{Na}-\text { late }}$ and $\mathrm{Na}^{+}-\mathrm{H}^{+}$exchange currents were ameliorated after empagliflozin treatment. This may at least in part be related to the effect of empagliflozin on cardiac ion homeostasis, and may contribute to the cardiac benefits in DM patients. Baartscheer et al. [36] have found that empagliflozin $(1 \mu \mathrm{M})$ directly regulates cytoplasmic $\mathrm{Na}^{+}$and $\mathrm{Ca}^{2+}$ in cardiomyocytes. Our study also found that acute administration of empagliflozin $(1 \mu \mathrm{M})$ reduced APD, $\mathrm{I}_{\mathrm{Na}-\text { late, }}$ and ROS in DM ventricular myocytes, which was similar to the results seen from the in vivo treatment of empagliflozin in DM rat model. Previous study has shown that patients have peak plasma concentration of empagliflozin close to $1 \mu \mathrm{M}$ [37], thus the concentration of empagliflozin used in this study is clinically relevant. These findings suggest that empagliflozin may have direct effects on cardiac disorder in DM rats. However, the hypoglycemic effects of empagliflozin may have also contributed to the improvements in the cardiac condition in DM cardiomyopathy. 
We evaluated ROS production in the DM hearts, and found that both cytosolic and mitochondria ROS production were decreased after treatment with empagliflozin. $\mathrm{Ca}^{2+}$ sparks induced by RyR hyperphosphorylation can lead to mitochondrial $\mathrm{Ca}^{2+}$ overload, thereby facilitating ROS production.

In addition, mitochondria-derived ROS can induce local $\mathrm{ER} \mathrm{Ca}^{2+}$ release events, which increased spark frequency in cardiomyocytes. The reduction of $\mathrm{Ca}^{2+}$ sparks by empagliflozin may contribute to its inhibitory effect on ROS production [38]. Moreover, the hypoglycemic effects of empagliflozin may reduce ROS, since hyperglycemia and insulin resistance result in excess ROS production [39]. The reduction in ROS production after empagliflozin treatment may have contributed to attenuating the increase in $\mathrm{Ca}^{2+}$ sparks in the empagliflozin-treated DM hearts. However, characterization of the mechanical function in arrhythmogenesis and heart failure models are needed to further understand the cardioprotective effect of empagliflozin in DM hearts. We also found that the blood glucose level was lower in our STZ-induced DM rats treated with empagliflozin. Improvements in glycemic control through non-insulin-dependent pathways with SGLT2 inhibitors are also important as an add-on treatment for type $1 \mathrm{DM}$, as improved glycemic control can reduce end-organ complications in DM patients. The lower $\mathrm{I}_{\mathrm{Na}-\text { late }}, \mathrm{Na}^{+} / \mathrm{H}^{+}$exchanger, $\mathrm{ROS}$ and $\mathrm{Ca}^{2+}$ sparks in the empagliflozin-treated DM ventricular myocytes than in the DM ventricular myocytes suggests that empagliflozin may possess anti-arrhythmic potential. Therefore, it would be interesting to perform further tests to verify the anti-arrhythmic effect of empagliflozin. Figure 8 details the potential action mechanisms of empagliflozin in the DM hearts in this study. Empagliflozin treatment may reverse DM-induced $\mathrm{Ca}^{2+} / \mathrm{Na}^{+}$dysregulation by decreasing ROS and ionic channel modification in cardiomyocytes, leading to improvements in cardiac function, attenuation of ventricular hypertrophy, and correction of prolonged QT intervals.

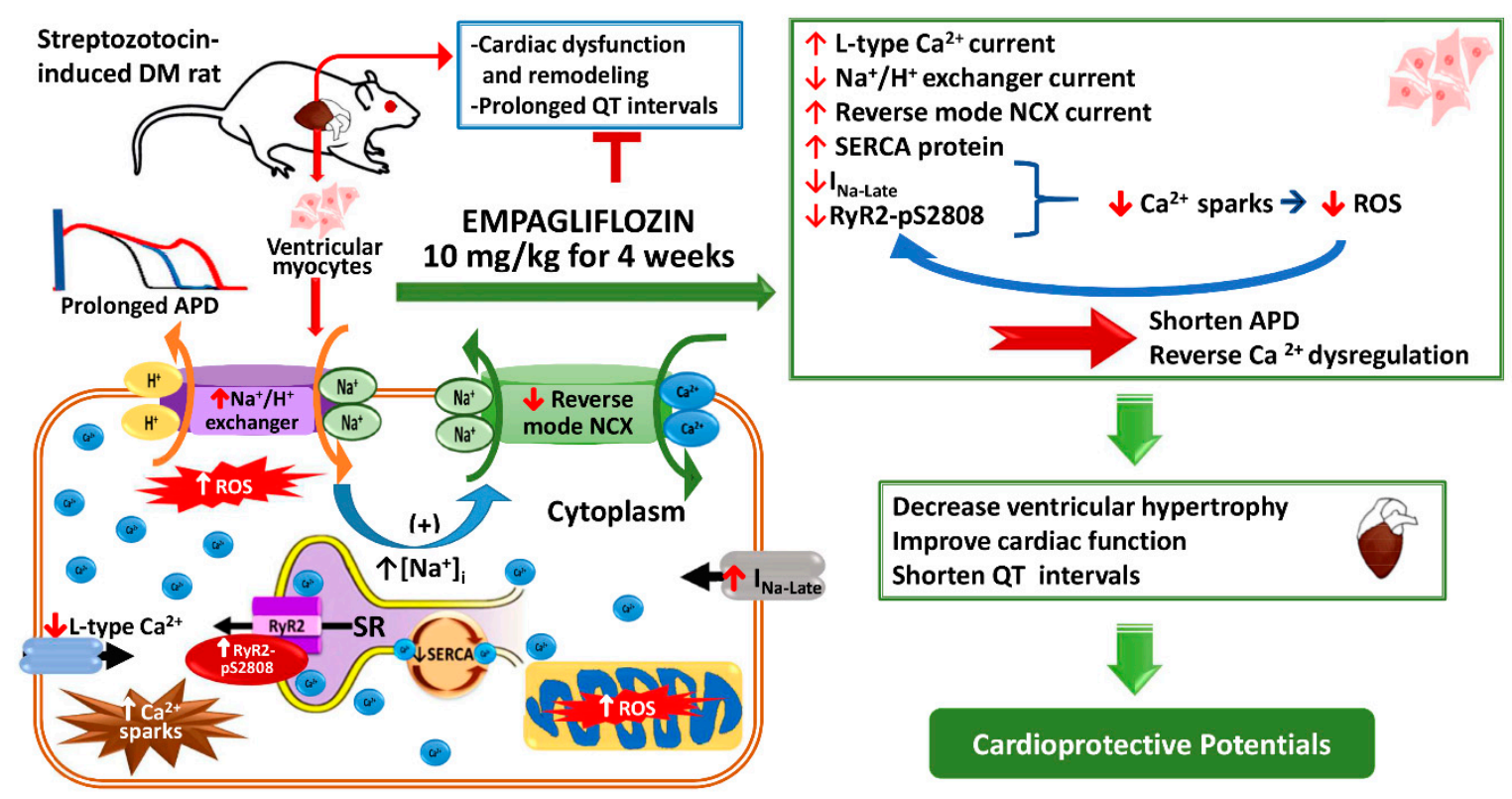

Figure 8. Schematic illustration of the proposed mechanism of action of empagliflozin in DM hearts. Empagliflozin treatment may reverse DM-induced $\mathrm{Ca}^{2+} / \mathrm{Na}^{+}$dysregulation by decreasing $\mathrm{ROS}$ and ionic channel modification in cardiomyocytes, leading to improvements in cardiac function, attenuation of ventricular hypertrophy, and correction of prolonged QT intervals. APD: Action Potential Duration DM: Diabetes Mellitus; $\mathrm{Ca}^{2+}$ : Calcium; $\mathrm{H}^{+}$: Hydrogen; $\left[\mathrm{Na}^{+}\right]_{\mathrm{i}}$ : Intracellular Sodium; $\mathrm{I}_{\mathrm{Na}-L a t e}$ : Late Sodium Current; $\mathrm{Na}^{+}$: Sodium; NCX: Sodium Calcium Exchanger; QT: QT interval; $\mathrm{Na}^{+}$: Sodium; ROS: Reactive Oxygen Species; RyR2: Ryanodine Receptor; RyR2-pS2808: Phosphorylated RyR2 at serine 2808; SR: Sarcoplasmic Reticulum; SERCA: Sarcoplasmic Reticulum ATPase; STZ: Streptozotocin. 


\section{Study Limitation}

First, T-type $\mathrm{Ca}^{2+}$ channels have been shown to be re-expressed in hypertrophic ventricular myocytes [40]. However, we did not measure T-type $\mathrm{Ca}^{2+}$ channels in this study because they contribute less to the trigger for $\mathrm{Ca}^{2+}$ release [40]. Second, APD is controlled not only by $\mathrm{Ca}^{2+} \mathrm{or} \mathrm{Na}^{+}$ channels but also by potassium $\left(\mathrm{K}^{+}\right)$channels.

However, we mainly focused on the effects of empagliflozin on $\mathrm{Ca}^{2+} / \mathrm{Na}^{+}$regulation in DM cardiomyocytes, and did not examine the functional changes in $\mathrm{K}^{+}$channels. Finally, the experimental setting in this study may not fully correlate with clinical features. Most DM patients have faster resting heart rate due to autonomic neuropathy [41,42]. On the contrary, the DM rats had a lower heart rate compared to the control in this study. STZ-induced DM resembles human type $1 \mathrm{DM}$, which is associated with a lower body weight. Nevertheless, most DM patients have a higher body weight than subjects without DM, since type $2 \mathrm{DM}$ is more common. This study showed that empagliflozin treatment did not reverse the lower body weight in DM rats, which may have been caused by inadequate glycemic control.

\section{Methods}

\subsection{Ethical Approval}

This investigation conformed to the institutional Guide for the Care and Use of Laboratory Animals and the Guide for the Care and Use of Laboratory Animals published by the US National Institutes of Health (NIH publication no. 85-23, revised 1996), and was approved on April 25, 2016 by the Institutional Animal Care and Use Committee of Taipei Medical University (LAC-2016-0425).

\subsection{Induction of DM, Treatment and Tissue Harvesting}

Rats were housed in standard environmental conditions of low humidity and temperature $\left(21 \pm 2^{\circ} \mathrm{C}\right)$ with a 12-h light/dark cycle, and were maintained on commercial rat chow and tap water, ad libitum. To induce diabetes mellitus (DM), some of the 10-week-old male Wistar rats $(\sim 335 \pm 4.5 \mathrm{~g})$ received a single intraperitoneal injection of STZ $(65 \mathrm{mg} / \mathrm{kg}$, Sigma-Aldrich; St. Louis, MO, USA) after $10 \mathrm{~h}$ of overnight starvation [14,43]. DM was diagnosed according to a high fasting plasma glucose ( $\geq 15 \mathrm{mmol} / \mathrm{L})[14,43]$, as measured with a glucometer (Bayer Breeze 2 glucometer, Bayer Health Care, Mishawaka, IN, USA). Two weeks after the induction of DM (12 weeks of age), DM rats were randomly assigned to receive empagliflozin $(10 \mathrm{mg} / \mathrm{kg}$, po, Jardiance, Boehringer Ingelheim Pharmaceuticals, Inc., Ridgefield, CT, USA) [44] or vehicle (1 cc normal saline) once daily for 4 weeks by oral gavage. The rats were anesthetized by deep inhalation with $5 \%$ isoflurane [45], and sacrificed at 16 weeks of age. Body weights were measured prior to euthanasia. Each heart was rapidly excised, weighed, and dissected. Freshly isolated ventricular tissues were rinsed in a cold physiological saline solution and frozen in liquid nitrogen for protein isolation.

\subsection{Echocardiography and Electrocardiography Measurements}

Under isoflurane anesthesia (5\% for induction and 2\% for maintenance), transthoracic echocardiography was performed using a Vivid I ultrasound cardiovascular system (GE Healthcare, Haifa, Israel) at 16 weeks of age (6 weeks after receiving STZ) in the control and DM rats, with and without empagliflozin treatment. The following cardiac structures were measured using M-Mode tracing of the LV: LVEDd, LVESd, EDV, ESV, FS, and EF [46].

Electrocardiography was performed at 10 and 16 weeks of age, and electrocardiograms were recorded from standard lead II limb leads via a bio-amplifier (AD Instruments, Castle Hill, Australia), connected to a polygraph recorder (ML 845 Powerlab, AD Instruments) [47]. The results were continuously displayed throughout the experiments in the control and DM rats, with and without empagliflozin treatment. 
The systolic and diastolic BPs of the control and DM rats with and without empagliflozin treatment, were measured at 10 and 16 weeks of age using a non-invasive BP tail-cuff method (MK-2000, Muromachi Kikai, Tokyo, Japan) as described previously [47].

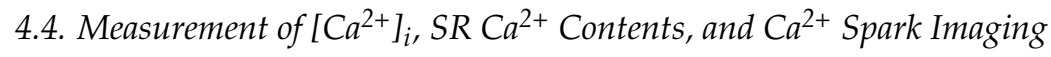

Freshly isolated rat ventricular myocytes were enzymatically dissociated using collagenase (type I, Sigma) and protease (type XIV, Sigma) after euthanasia as described previously [14]. $\left[\mathrm{Ca}^{2+}\right]_{\mathrm{i}}$ was recorded in single myocytes. Cells were loaded with a fluorescent $\mathrm{Ca}^{2+}(10 \mu \mathrm{M})$ fluo-3/AM for $30 \mathrm{~min}$ at room temperature. Excess extracellular dye was removed by changing the bath solution and allowing the intracellular hydrolysis of fluo-3/AM after $30 \mathrm{~min}$. Fluo-3 fluorescence was excited with a 488-nm line of an argon ion laser. The emission was recorded at $>515 \mathrm{~nm}$. For line scan imaging (8-bit), cells were repetitively scanned at 2-ms intervals. Fluorescence imaging was performed using a laser scanning confocal microscopic examination (Zeiss LSM 510, Carl Zeiss, Jena, Germany) and an inverted microscope (Axiovert 100, Carl Zeiss, Jena, Germany). The fluorescent signals were corrected for variation in dye concentration by normalizing the fluorescence $(F)$ against baseline fluorescence $\left(\mathrm{F}_{0}\right)$, to obtain reliable information about transient intracellular $\mathrm{Ca}^{2+}\left(\left[\mathrm{Ca}^{2+}\right]_{i}\right)$ changes from the baseline values $\left(\mathrm{F} / \mathrm{F}_{0}\right)$ and to exclude variations in the fluorescence intensity by different volumes of injected dye. The $\left[\mathrm{Ca}^{2+}\right]_{i}$ transient, and decayed portion of the $\left[\mathrm{Ca}^{2+}\right]_{\mathrm{i}}$ transient were measured during a $1-\mathrm{Hz}$ field-stimulation with 10 -ms twice-threshold strength square-wave pulses. The $\left[\mathrm{Ca}^{2+}\right]_{i}$ was determined by the monoexponential least-squares fit. After achieving steady-state $\mathrm{Ca}^{2+}$ transients with repeated pulses from -40 to $0 \mathrm{mV}\left(1 \mathrm{~Hz}\right.$ for $5 \mathrm{~s}$ ), the $\mathrm{SR} \mathrm{Ca}^{2+}$ content was estimated by integrating the NCX current following application of $20 \mathrm{mM}$ of caffeine within $0.5 \mathrm{~s}$ while resting with the membrane potential clamped to $-40 \mathrm{mV}$ to cause SR Ca ${ }^{2+}$ release [48]. The total $\mathrm{SR} \mathrm{Ca}^{2+}$ content (expressed as millimoles of cytosol) was determined using this equation: SR Ca ${ }^{2+}$ content $=[(1+0.12)(\mathrm{Ccaff} / \mathrm{F} \times$ $1000)] /(\mathrm{Cm} \times 8.31 \times 8.44)$, where $\mathrm{Cm}$ is the membrane capacitance; F is Faraday's number; and the cell surface to volume ratio is $6.44 \mathrm{pF} / \mathrm{pL}[49,50]$.

$\mathrm{Ca}^{2+}$ sparks were detected using the line scan mode along a line parallel to the longitudinal axis of single freshly isolated rat ventricular myocytes, while avoiding the nuclei. Each line was composed of 512 pixels. $\mathrm{Ca}^{2+}$ sparks were detected as an increase in the signal mass (more than $1.3 \mathrm{~F} / \mathrm{F}_{0}$ ) of a $5-\mu \mathrm{m}$ section through the center of a $\mathrm{Ca}^{2+}$ spark, with no detectable increase in the adjacent $5-\mu \mathrm{m}$ section. The $\mathrm{Ca}^{2+}$ spark frequency was determined for each cell and normalized to the scanned cell length. Images were analyzed using both ImageJ and custom-made routines based on IDL (ITT Visual Information Solutions, CO, USA).

\subsection{AP and Ionic Currents}

A whole-cell patch-clamp using an Axopatch 1D amplifier (Axon Instruments, Foster City, CA, USA) was performed in the freshly isolated ventricular myocytes of rats at $35 \pm 1{ }^{\circ} \mathrm{C}$. Borosilicate glass electrodes (o.d., $1.8 \mathrm{~mm}$ ) were used with tip resistances of 3 5 $\mathrm{M} \Omega$. Before the formation of the membrane-pipette seal, the tip potentials were zeroed in Tyrode's solution. Junction potentials between the bath and pipette solution $(9 \mathrm{mV})$ were corrected for AP recordings. APs driven at $1 \mathrm{~Hz}$ were recorded in the current-clamp mode, and ionic currents were measured in the voltage-clamp mode. A small hyperpolarizing step from a holding potential of $-50 \mathrm{mV}$ to a test potential of $-55 \mathrm{mV}$ for $80 \mathrm{~ms}$ was delivered at the beginning of each experiment. The area under the capacitative currents curve was divided by the applied voltage step to obtain the total cell capacitance [51]. In most cases, $60 \% \sim 80 \%$ series resistance was electronically compensated. Micropipettes were filled with solutions containing (in mM): $\mathrm{CsCl} 130, \mathrm{MgCl}_{2} 1$, MgATP 5, HEPES 10, EGTA 10, NaGTP 0.1, and $\mathrm{Na}_{2}$ phosphocreatine 5, titrated to a $\mathrm{pH}$ of 7.2 with $\mathrm{CsOH}$ for $\mathrm{I}_{\mathrm{Ca}-\mathrm{L}} ; \mathrm{NaCl} 20, \mathrm{CsCl} 110, \mathrm{MgCl}_{2} 0.4, \mathrm{CaCl}_{2}$ 1.75, tetraethylammonium 20, 1,2-bis(2-aminophenoxy)ethane- $\mathrm{N}, \mathrm{N}, \mathrm{N}^{\prime}, \mathrm{N}^{\prime}$-tetraacetic acid (BAPTA) 5, glucose 5, MgATP 5, and HEPES 10, titrated to $\mathrm{pH}$ of 7.25 for NCX currents; $10 \mathrm{NaCl}, 130 \mathrm{CsCl}$, 5 EGTA, 5 HEPES, 5 glucose, and 5 ATP-Mg for the $\mathrm{I}_{\mathrm{Na} \text {-Late; }}$ and $\mathrm{KCl} 20$, $\mathrm{K}$ aspartate $110, \mathrm{MgCl}_{2} 1$, 
MgATP 5, HEPES 10, EGTA 0.5, LiGTP 0.1, and $\mathrm{Na}_{2}$ phosphocreatine 5, titrated to a $\mathrm{pH}$ of 7.2 with $\mathrm{KOH}$ for the APs. Voltage command pulses were generated with a 12-bit digital-to-analog converter controlled using pCLAMP software (Axon Instruments). Recordings were low pass-filtered at half the sampling frequency. The APA was determined by measuring the difference between the RMP and the peak of AP depolarization. The APD at repolarization extents of $90 \%, 50 \%$, and $20 \%$ of the amplitude were measured, and respectively designated as $\mathrm{APD}_{90}, \mathrm{APD}_{50}$, and $\mathrm{APD}_{20}$.

$\mathrm{I}_{\mathrm{Ca}-\mathrm{L}}$ was measured as an inward current during depolarization from a holding potential of $-50 \mathrm{mV}$ to test potentials ranging from -40 to $+60 \mathrm{mV}$ in $10-\mathrm{mV}$ steps for $300 \mathrm{~ms}$ at a frequency of $0.1 \mathrm{~Hz} . \mathrm{NaCl}$ and $\mathrm{KCl}$ in the external solution were respectively replaced by tetraethylammonium chloride and $\mathrm{CsCl}$. The NCX current was elicited by depolarizing pulses between -100 and $+100 \mathrm{mV}$ from a holding potential of $-40 \mathrm{mV}$ for $300 \mathrm{~ms}$ at a frequency of $0.1 \mathrm{~Hz}$. Amplitudes of NCX currents were measured as 10-mM nickel-sensitive currents. The external solution consisted of (in $\mathrm{mM}$ ) $\mathrm{NaCl}$ $140, \mathrm{CaCl}_{2} 2, \mathrm{MgCl}_{2}$ 1, HEPES 5, and glucose 10, with the $\mathrm{pH}$ adjusted to 7.4 and $10 \mu \mathrm{M}$ strophanthidin (to block the $\mathrm{Na}^{+} / \mathrm{K}^{+}$pump), $10 \mu \mathrm{M}$ nitrendipine (a dihydropyridine antagonist), and $100 \mu \mathrm{M}$ niflumic acid (to block $\mathrm{Ca}^{2+}$-activated $\mathrm{Cl}^{-}$currents).

$\mathrm{I}_{\mathrm{Na}-L a t e}$ was recorded with an external solution containing (in $\mathrm{mM}$ ): $\mathrm{NaCl} 130, \mathrm{CsCl} 5, \mathrm{MgCl}_{2} 1$, $\mathrm{CaCl}_{2} 1$, HEPES 10 , and glucose 10 at a $\mathrm{pH}$ of 7.4 with $\mathrm{NaOH}$ by a step/ramp protocol $(-100 \mathrm{mV}$ stepped to $+20 \mathrm{mV}$ at room temperature for $100 \mathrm{~ms}$, then ramped back to $-100 \mathrm{mV}$ over $100 \mathrm{~ms})$. The tetrodotoxin $(30 \mu \mathrm{M})$-sensitive portion of the current traces, obtained when the voltage was ramped back to $-100 \mathrm{mV}$, was measured as the $\mathrm{I}_{\mathrm{Na} \text {-Late }}$ current [51].

To measure $\mathrm{Na}^{+} / \mathrm{H}^{+}$exchanger current, a whole-cell camp with patch electrodes of 1.5-3.0 $\mathrm{M} \Omega$ resistance were filled with solution consisting of (in $\mathrm{mM}) 20 \mathrm{KCl}, 130 \mathrm{~K}$-Aspartate, $1 \mathrm{MgCl}_{2}\left(6 \mathrm{H}_{2} \mathrm{O}\right)$, $10 \mathrm{HEPES} / \mathrm{KOH}$ (pH 7.3), and 0.005 EGTA. The external solution consisted of (in mM) $150 \mathrm{NaCl}$, $5.4 \mathrm{KCl}, 3.6 \mathrm{CaCl}_{2}, 1.2 \mathrm{MgCl}_{2}\left(6 \mathrm{H}_{2} \mathrm{O}\right), 20$ glucose, and $5 \mathrm{HEPES} / \mathrm{NaOH}$ (pH 7.4). All groups of freshly isolated rat ventricular myocytes were stimulated with $40 \mathrm{~ms}$ depolarizing pulses from -45 to $0 \mathrm{mV}$ at $3 \mathrm{~Hz}[52]$.

\subsection{Measurement of Cell Size and Intracellular ROS and $\mathrm{Na}^{+}$}

The cross-sectional area in the isolated single ventricular myocytes were imaged using a confocal laser scan microscope (Zeiss LSM 510, Carl Zeiss) and images were processed by ImageJ measurement tools [53]. We used CellROX green (Life Technologies, Grand Island, NY, USA) to assess cytosolic ROS production, MitoSOX Red (Life Technologies) to determine ROS production in the mitochondria, and Asante NaTRIUM Green-2 AM (Teflabs, Austin, TX, USA) to evaluate the cytosolic $\mathrm{Na}^{+}$concentration of freshly isolated ventricular myocytes in the control, DM, and empagliflozin-treated DM rats. Experiments were carried out using a laser scanning confocal microscope (Zeiss LSM 510, Carl Zeiss) and an inverted microscope (Axiovert 100) with a 63x1.25 numerical aperture oil immersion objective, as described previously [54]. Freshly isolated ventricular myocytes were kept in normal Tyrode's solution (containing in $\mathrm{mM}$ ): $\mathrm{NaCl} 137, \mathrm{KCl} 5.4, \mathrm{CaCl}_{2} 1.8, \mathrm{MgCl}_{2}$ 0.5, and HEPES 10, with appropriate fluorescent dye of $10 \mu \mathrm{M}$ CellROX green, $2 \mu \mathrm{M}$ MitoSOX Red, or $5 \mu \mathrm{mol} / \mathrm{L}$ Asante NaTRIUM Green-2 AM. CellROX green, MitoSOX Red, and Asante NaTRIUM Green-2 AM were excited at $488 \mathrm{~nm}$, and fluorescence signals were acquired at wavelengths of $>505 \mathrm{~nm}$ in the XY mode of the confocal system. In this experiment, ventricular myocytes were paced at $1 \mathrm{~Hz}$. Fluorescent images were analyzed using Image-Pro plus 6.0 and Sigma plot 12 software, as described previously [51].

\subsection{Western Blot Analysis}

Equal amounts of proteins were resolved using sodium dodecyl sulfate polyacrylamide gel electrophoresis as described previously [43]. Blots were probed with antibodies against sarcoplasmic reticulum ATPase (SERCA2a, cat. no. Sc-8094; 1:1000; Santa Cruz Biotechnology, CA, USA), ryanodine receptor 2 (RyR2; cat. no. MA3-916; 1:1000; Affinity Bioreagents, Golden, CO, USA), phosphorylated RyR2 at serine 2808 (RyR2-pS2808; cat. no. A010-30AP; 1:000; Badrilla, UK), and secondary antibodies 
conjugated with horseradish peroxidase (Leinco Technology, St. Louis, MO, USA). Bound antibodies were detected using an enhanced chemiluminescence detection system (Millipore, St. Louis, MO, USA) and analyzed with AlphaEaseFC software (Alpha Innotech, San Leandro, CA, USA).

Targeted bands were normalized to cardiac glyceraldehyde 3-phosphate dehydrogenase (GAPDH; cat. no. M171-7; 1:1000; Sigma-Aldrich) to confirm equal protein loading.

\subsection{Statistical Analysis}

All quantitative data are expressed as the mean \pm standard error of the mean (SEM). Statistical significance between different groups was determined using an unpaired $t$-test or one-way analysis of variance (ANOVA) with Duncan's method, using Systat software SigmaPlot version 12 (Systat Software Inc., San Jose, CA, USA) for multiple comparisons as appropriate. A $p$ value of $<0.05$ was considered to be statistically significant. The sample size was calculated according to the ejection fraction with an estimated standard deviation of 3 . The required sample size was 7 under a type I error of $5 \%$ with a statistical power of $80 \%$.

Author Contributions: Conceptualization and Designed the Experiments: T.-I.L., Y.-C.C., Y.-H.K. and Y.-J.C.; Performed the Experiments: T.-I.L., Y.-C.C., C.-C.C.; Formal Analysis: C.-C.C., Y.-K.L., and Y.-Y.L.; Drafting Graphical Abstract and Figure 7: T.-I.L. and Y.-Y.L.; Writing Manuscript Draft: T.-I.L. and Y.-K.L.; Writing-Review and Editing: Y.-H.K. and Y.-J.C.

Acknowledgments: The present work was supported by grants from Taipei Medical University, Wan Fang Hospital (105-wf-eva-06, 105-swf-02, 105-wf-eva-08, 105-wf-eva-14, 106-eva-02, 106-eva-06, 106-swf-01, 107-wf-swf-02, and 107-wf-eva-13, 108-wf-swf-02), Ministry of Science and Technology of Taiwan (MOST105-2314-B-016-035-MY3, MOST105-2628-B-038-012-MY3, MOST105-2314-B-038-026-, MOST105-2314-B281-004-MY2, MOST105-2314-B-038-059-MY3, and MOST106-2314-B-038-060-, MOST107-2314-B-038-016-), Chi-Mei Medical Center (107CM-TMU-04 and CMNDMC10707), and the Ministry of National Defense-Medical Affairs Bureau, Taiwan (MAB-107-044).

Conflicts of Interest: The authors declare no conflict of interest.

\section{References}

1. Stamler, J.; Vaccaro, O.; Neaton, J.D.; Wentworth, D. Diabetes, other risk factors, and 12-yr cardiovascular mortality for men screened in the Multiple Risk Factor Intervention Trial. Diabetes Care 1993, 16, 434-444. [CrossRef]

2. Morrish, N.J.; Wang, S.L.; Stevens, L.K.; Fuller, J.H.; Keen, H. Mortality and causes of death in the WHO Multinational Study of Vascular Disease in Diabetes. Diabetologia 2001, 44 (Suppl. 2), S14-S21. [CrossRef]

3. Scognamiglio, R.; Avogaro, A.; Negut, C.; Piccolotto, R.; Vigili de Kreutzenberg, S.; Tiengo, A. Early myocardial dysfunction in the diabetic heart: Current research and clinical applications. Am. J. Cardiol. 2004, 93, 17A-20A. [CrossRef] [PubMed]

4. Fang, Z.Y.; Prins, J.B.; Marwick, T.H. Diabetic cardiomyopathy: Evidence, mechanisms, and therapeutic implications. Endocr. Rev. 2004, 25, 543-567. [CrossRef] [PubMed]

5. Pfister, M.; Whaley, J.M.; Zhang, L.; List, J.F. Inhibition of SGLT2: A novel strategy for treatment of type 2 diabetes mellitus. Clin. Pharmacol. Ther. 2011, 89, 621-625. [CrossRef]

6. Henry, R.R.; Thakkar, P.; Tong, C.; Polidori, D.; Alba, M. Efficacy and Safety of Canagliflozin, a Sodium-Glucose Cotransporter 2 Inhibitor, as Add-on to Insulin in Patients with Type 1 Diabetes. Diabetes Care 2015, 38, 2258-2265. [CrossRef]

7. Van den Mooter, L.; Caerels, S.; Mathieu, C. Efficacy of dapagliflozin as an adjunct therapy in patients with inadequately controlled type 1 diabetes mellitus. Expert Opin. Pharmacother. 2018, 19, 617-622. [CrossRef]

8. Nauck, M.A. Update on developments with SGLT2 inhibitors in the management of type 2 diabetes. Drug Des. Dev. Ther. 2014, 8, 1335-1380. [CrossRef]

9. Zinman, B.; Wanner, C.; Lachin, J.M.; Fitchett, D.; Bluhmki, E.; Hantel, S.; Mattheus, M.; Devins, T.; Johansen, O.E.; Woerle, H.J.; et al. Empagliflozin, Cardiovascular Outcomes, and Mortality in Type 2 Diabetes. N. Engl. J. Med. 2015, 373, 2117-2128. [CrossRef] [PubMed] 
10. Shattock, M.J.; Ottolia, M.; Bers, D.M.; Blaustein, M.P.; Boguslavskyi, A.; Bossuyt, J.; Bridge, J.H.; Chen-Izu, Y.; Clancy, C.E.; Edwards, A.; et al. $\mathrm{Na}^{+} / \mathrm{Ca}^{2+}$ exchange and $\mathrm{Na}^{+} / \mathrm{K}^{+}$-ATPase in the heart. J. Physiol. 2015, 593, 1361-1382. [CrossRef]

11. Fein, F.S.; Aronson, R.S.; Nordin, C.; Miller-Green, B.; Sonnenblick, E.H. Altered myocardial response to ouabain in diabetic rats: Mechanics and electrophysiology. J. Mol. Cell. Cardiol. 1983, 15, 769-784. [CrossRef]

12. Lambert, R.; Srodulski, S.; Peng, X.; Margulies, K.B.; Despa, F.; Despa, S. Intracellular Na ${ }^{+}$Concentration $\left(\left[\mathrm{Na}^{+}\right]_{\mathrm{i}}\right)$ Is Elevated in Diabetic Hearts Due to Enhanced $\mathrm{Na}^{+}$-Glucose Cotransport. J. Am. Heart Assoc. 2015, 4, e002183. [CrossRef] [PubMed]

13. Bugger, H.; Abel, E.D. Molecular mechanisms of diabetic cardiomyopathy. Diabetologia 2014, 57, 660-671. [CrossRef]

14. Lee, T.I.; Chen, Y.C.; Kao, Y.H.; Hsiao, F.C.; Lin, Y.K.; Chen, Y.J. Rosiglitazone induces arrhythmogenesis in diabetic hypertensive rats with calcium handling alteration. Int. J. Cardiol. 2013, 165, 299-307. [CrossRef] [PubMed]

15. Lee, T.I.; Kao, Y.H.; Chen, Y.C.; Huang, J.H.; Hsu, M.I.; Chen, Y.J. The dipeptidyl peptidase-4 inhibitor-sitagliptin modulates calcium dysregulation, inflammation, and PPARs in hypertensive cardiomyocytes. Int. J. Cardiol. 2013, 168, 5390-5395. [CrossRef]

16. Huang, J.H.; Chen, Y.C.; Lee, T.I.; Kao, Y.H.; Chazo, T.F.; Chen, S.A.; Chen, Y.J. Glucagon-like peptide-1 regulates calcium homeostasis and electrophysiological activities of HL-1 cardiomyocytes. Peptides 2016, 78, 91-98. [CrossRef] [PubMed]

17. Trost, S.U.; Belke, D.D.; Bluhm, W.F.; Meyer, M.; Swanson, E.; Dillmann, W.H. Overexpression of the sarcoplasmic reticulum $\mathrm{Ca}^{2+}$-ATPase improves myocardial contractility in diabetic cardiomyopathy. Diabetes 2002, 51, 1166-1171. [CrossRef] [PubMed]

18. Hattori, Y.; Matsuda, N.; Kimura, J.; Ishitani, T.; Tamada, A.; Gando, S.; Kemmotsu, O.; Kanno, M. Diminished function and expression of the cardiac $\mathrm{Na}^{+}-\mathrm{Ca}^{2+}$ exchanger in diabetic rats: Implication in $\mathrm{Ca}^{2+}$ overload. J. Physiol. 2000, 527 Pt 1, 85-94. [CrossRef]

19. Teshima, Y.; Takahashi, N.; Saikawa, T.; Hara, M.; Yasunaga, S.; Hidaka, S.; Sakata, T. Diminished expression of sarcoplasmic reticulum $\mathrm{Ca}^{2+}$-ATPase and ranodine sensitive $\mathrm{Ca}^{2+}$ Channel mRNA in streptozotocin-induced diabetic rat heart. J. Mol. Cell. Cardiol. 2000, 32, 655-664. [CrossRef]

20. Vetter, R.; Rehfeld, U.; Reissfelder, C.; Weiss, W.; Wagner, K.D.; Gunther, J.; Hammes, A.; Tschope, C.; Dillmann, W.; Paul, M. Transgenic overexpression of the sarcoplasmic reticulum $\mathrm{Ca}^{2+}$ ATPase improves reticular $\mathrm{Ca}^{2+}$ handling in normal and diabetic rat hearts. FASEB J. 2002, 16, 1657-1659. [CrossRef]

21. Fein, F.S.; Zola, B.E.; Malhotra, A.; Cho, S.; Factor, S.M.; Scheuer, J.; Sonnenblick, E.H. Hypertensive-diabetic cardiomyopathy in rats. Am. J. Physiol. 1990, 258, H793-H805. [CrossRef] [PubMed]

22. Kahn, J.K.; Sisson, J.C.; Vinik, A.I. QT interval prolongation and sudden cardiac death in diabetic autonomic neuropathy. J. Clin. Endocrinol. Metab. 1987, 64, 751-754. [CrossRef]

23. Magyar, J.; Rusznak, Z.; Szentesi, P.; Szucs, G.; Kovacs, L. Action potentials and potassium currents in rat ventricular muscle during experimental diabetes. J. Mol. Cell. Cardiol. 1992, 24, 841-853. [CrossRef]

24. Habibi, J.; Aroor, A.R.; Sowers, J.R.; Jia, G.; Hayden, M.R.; Garro, M.; Barron, B.; Mayoux, E.; Rector, R.S.; Whaley-Connell, A.; et al. Sodium glucose transporter 2 (SGLT2) inhibition with empagliflozin improves cardiac diastolic function in a female rodent model of diabetes. Cardiovasc. Diabetol. 2017, 16, 9. [CrossRef] [PubMed]

25. Pacher, P.; Ungvari, Z.; Nanasi, P.P.; Kecskemeti, V. Electrophysiological changes in rat ventricular and atrial myocardium at different stages of experimental diabetes. Acta Physiol. Scand. 1999, 166, 7-13. [CrossRef]

26. Despa, S. Myocyte $\left[\mathrm{Na}^{+}\right]_{\mathrm{i}}$ Dysregulation in Heart Failure and Diabetic Cardiomyopathy. Front. Physiol. 2018, 9, 1303. [CrossRef]

27. Choi, K.M.; Zhong, Y.; Hoit, B.D.; Grupp, I.L.; Hahn, H.; Dilly, K.W.; Guatimosim, S.; Lederer, W.J.; Matlib, M.A. Defective intracellular $\mathrm{Ca}^{2+}$ signaling contributes to cardiomyopathy in Type 1 diabetic rats. Am. J. Physiol. Heart Circ. Physiol. 2002, 283, H1398-H1408. [CrossRef]

28. Kotsanas, G.; Delbridge, L.M.; Wendt, I.R. Stimulus interval-dependent differences in $\mathrm{Ca}^{2+}$ transients and contractile responses of diabetic rat cardiomyocytes. Cardiovasc. Res. 2000, 46, 450-462. [CrossRef]

29. Asghar, O.; Al-Sunni, A.; Khavandi, K.; Khavandi, A.; Withers, S.; Greenstein, A.; Heagerty, A.M.; Malik, R.A. Diabetic cardiomyopathy. Clin. Sci. 2009, 116, 741-760. [CrossRef] 
30. Hammoudi, N.; Jeong, D.; Singh, R.; Farhat, A.; Komajda, M.; Mayoux, E.; Hajjar, R.; Lebeche, D. Empagliflozin Improves Left Ventricular Diastolic Dysfunction in a Genetic Model of Type 2 Diabetes. Cardiovasc. Drugs Ther. 2017, 31, 233-246. [CrossRef]

31. Yuill, K.H.; Al Kury, L.T.; Howarth, F.C. Characterization of L-type calcium channel activity in atrioventricular nodal myocytes from rats with streptozotocin-induced Diabetes mellitus. Physiol. Rep. 2015, 3, 12632. [CrossRef] [PubMed]

32. Pereira, L.; Matthes, J.; Schuster, I.; Valdivia, H.H.; Herzig, S.; Richard, S.; Gomez, A.M. Mechanisms of $\left[\mathrm{Ca}^{2+}\right]_{\mathrm{i}}$ transient decrease in cardiomyopathy of $\mathrm{db} / \mathrm{db}$ type 2 diabetic mice. Diabetes 2006, 55, 608-615. [CrossRef] [PubMed]

33. Wang, D.W.; Kiyosue, T.; Shigematsu, S.; Arita, M. Abnormalities of $\mathrm{K}^{+}$and $\mathrm{Ca}^{2+}$ currents in ventricular myocytes from rats with chronic diabetes. Am. J. Physiol. 1995, 269, H1288-H1296. [CrossRef] [PubMed]

34. Chattou, S.; Diacono, J.; Feuvray, D. Decrease in sodium-calcium exchange and calcium currents in diabetic rat ventricular myocytes. Acta Physiol. Scand. 1999, 166, 137-144. [CrossRef]

35. Lu, Z.; Jiang, Y.P.; Xu, X.H.; Ballou, L.M.; Cohen, I.S.; Lin, R.Z. Decreased L-type Ca ${ }^{2+}$ current in cardiac myocytes of type 1 diabetic Akita mice due to reduced phosphatidylinositol 3-kinase signaling. Diabetes 2007, 56, 2780-2789. [CrossRef]

36. Baartscheer, A.; Schumacher, C.A.; Wust, R.C.; Fiolet, J.W.; Stienen, G.J.; Coronel, R.; Zuurbier, C.J. Empagliflozin decreases myocardial cytoplasmic $\mathrm{Na}^{+}$through inhibition of the cardiac $\mathrm{Na}^{+} / \mathrm{H}^{+}$exchanger in rats and rabbits. Diabetologia 2017, 60, 568-573. [CrossRef] [PubMed]

37. Laffel, L.M.B.; Tamborlane, W.V.; Yver, A.; Simons, G.; Wu, J.; Nock, V.; Hobson, D.; Hughan, K.S.; Kaspers, S.; Marquard, J. Pharmacokinetic and pharmacodynamic profile of the sodium-glucose co-transporter-2 inhibitor empagliflozin in young people with Type 2 diabetes: A randomized trial. Diabet. Med. 2018, 35, 1096-1104. [CrossRef] [PubMed]

38. Davidson, S.M.; Duchen, M.R. Calcium microdomains and oxidative stress. Cell Calcium 2006, 40, 561-574. [CrossRef]

39. Teshima, Y.; Takahashi, N.; Nishio, S.; Saito, S.; Kondo, H.; Fukui, A.; Aoki, K.; Yufu, K.; Nakagawa, M.; Saikawa, T. Production of reactive oxygen species in the diabetic heart. Roles of mitochondria and NADPH oxidase. Circ. J. 2014, 78, 300-306. [CrossRef]

40. Ono, K.; Iijima, T. Cardiac T-type Ca ${ }^{2+}$ channels in the heart. J. Mol. Cell. Cardiol. 2010, 48, 65-70. [CrossRef]

41. Fakhrzadeh, H.; Yamini-Sharif, A.; Sharifi, F.; Tajalizadekhoob, Y.; Mirarefin, M.; Mohammadzadeh, M.; Sadeghian, S.; Badamchizadeh, Z.; Larijani, B. Cardiac autonomic neuropathy measured by heart rate variability and markers of subclinical atherosclerosis in early type 2 diabetes. ISRN Endocrinol. 2012, 2012, 168264. [CrossRef]

42. Freccero, C.; Svensson, H.; Bornmyr, S.; Wollmer, P.; Sundkvist, G. Sympathetic and parasympathetic neuropathy are frequent in both type 1 and type 2 diabetic patients. Diabetes Care 2004, 27, 2936-2941. [CrossRef] [PubMed]

43. Lee, T.I.; Kao, Y.H.; Chen, Y.C.; Pan, N.H.; Chen, Y.J. Oxidative stress and inflammation modulate peroxisome proliferator-activated receptors with regional discrepancy in diabetic heart. Eur. J. Clin. Investig. 2010, 40, 692-699. [CrossRef]

44. Hansen, H.H.; Jelsing, J.; Hansen, C.F.; Hansen, G.; Vrang, N.; Mark, M.; Klein, T.; Mayoux, E. The sodium glucose cotransporter type 2 inhibitor empagliflozin preserves beta-cell mass and restores glucose homeostasis in the male zucker diabetic fatty rat. J. Pharmacol. Exp. Ther. 2014, 350, 657-664. [CrossRef] [PubMed]

45. Chung, C.C.; Hsu, R.C.; Kao, Y.H.; Liou, J.P.; Lu, Y.Y.; Chen, Y.J. Androgen attenuates cardiac fibroblasts activations through modulations of transforming growth factor-beta and angiotensin II signaling. Int. J. Cardiol. 2014, 176, 386-393. [CrossRef] [PubMed]

46. Kao, Y.H.; Liou, J.P.; Chung, C.C.; Lien, G.S.; Kuo, C.C.; Chen, S.A.; Chen, Y.J. Histone deacetylase inhibition improved cardiac functions with direct antifibrotic activity in heart failure. Int. J. Cardiol. 2013, 168, 4178-4183. [CrossRef] [PubMed]

47. Lee, T.I.; Kao, Y.H.; Chen, Y.C.; Pan, N.H.; Lin, Y.K.; Chen, Y.J. Cardiac peroxisome-proliferator-activated receptor expression in hypertension co-existing with diabetes. Clin. Sci. 2011, 121, 305-312. [CrossRef] [PubMed] 
48. Suenari, K.; Chen, Y.C.; Kao, Y.H.; Cheng, C.C.; Lin, Y.K.; Chen, Y.J.; Chen, S.A. Discrepant electrophysiological characteristics and calcium homeostasis of left atrial anterior and posterior myocytes. Basic Res. Cardiol. 2011, 106, 65-74. [CrossRef]

49. Hove-Madsen, L.; Llach, A.; Bayes-Genis, A.; Roura, S.; Rodriguez Font, E.; Aris, A.; Cinca, J. Atrial fibrillation is associated with increased spontaneous calcium release from the sarcoplasmic reticulum in human atrial myocytes. Circulation 2004, 110, 1358-1363. [CrossRef]

50. Lu, Y.Y.; Chen, Y.C.; Kao, Y.H.; Lin, Y.K.; Yeh, Y.H.; Chen, S.A.; Chen, Y.J. Colchicine modulates calcium homeostasis and electrical property of HL-1 cells. J. Cell. Mol. Med. 2016, 20, 1182-1190. [CrossRef]

51. Huang, S.Y.; Chen, Y.C.; Kao, Y.H.; Hsieh, M.H.; Lin, Y.K.; Chung, C.C.; Lee, T.I.; Tsai, W.C.; Chen, S.A.; Chen, Y.J. Fibroblast growth factor 23 dysregulates late sodium current and calcium homeostasis with enhanced arrhythmogenesis in pulmonary vein cardiomyocytes. Oncotarget 2016, 7, 69231-69242. [CrossRef] [PubMed]

52. Kondratev, D.; Christ, A.; Gallitelli, M.F. Inhibition of the $\mathrm{Na}^{+}-\mathrm{H}^{+}$exchanger with cariporide abolishes stretch-induced calcium but not sodium accumulation in mouse ventricular myocytes. Cell Calcium 2005, 37, 69-80. [CrossRef] [PubMed]

53. Parikh, S.S.; Blackwell, D.J.; Gomez-Hurtado, N.; Frisk, M.; Wang, L.; Kim, K.; Dahl, C.P.; Fiane, A.; Tonnessen, T.; Kryshtal, D.O.; et al. Thyroid and Glucocorticoid Hormones Promote Functional T-Tubule Development in Human-Induced Pluripotent Stem Cell-Derived Cardiomyocytes. Circ. Res. 2017, 121, 1323-1330. [CrossRef] [PubMed]

54. Viatchenko-Karpinski, S.; Kornyeyev, D.; El-Bizri, N.; Budas, G.; Fan, P.; Jiang, Z.; Yang, J.; Anderson, M.E.; Shryock, J.C.; Chang, C.P.; et al. Intracellular $\mathrm{Na}^{+}$overload causes oxidation of CaMKII and leads to $\mathrm{Ca}^{2+}$ mishandling in isolated ventricular myocytes. J. Mol. Cell. Cardiol. 2014, 76, 247-256. [CrossRef] [PubMed]

(C) 2019 by the authors. Licensee MDPI, Basel, Switzerland. This article is an open access article distributed under the terms and conditions of the Creative Commons Attribution (CC BY) license (http:/ / creativecommons.org/licenses/by/4.0/). 